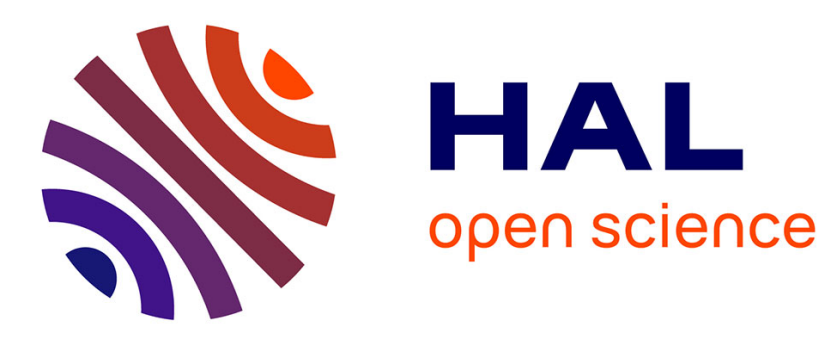

\title{
Insight in nAChR subtype selectivity from AChBP crystal structures
}

Prakash Rucktooa, August B. Smit, Titia K. Sixma

\section{To cite this version:}

Prakash Rucktooa, August B. Smit, Titia K. Sixma. Insight in nAChR subtype selectivity from AChBP crystal structures. Biochemical Pharmacology, 2009, 78 (7), pp.777. 10.1016/j.bcp.2009.06.098 . hal-00509510

\section{HAL Id: hal-00509510 https://hal.science/hal-00509510}

Submitted on 13 Aug 2010

HAL is a multi-disciplinary open access archive for the deposit and dissemination of scientific research documents, whether they are published or not. The documents may come from teaching and research institutions in France or abroad, or from public or private research centers.
L'archive ouverte pluridisciplinaire HAL, est destinée au dépôt et à la diffusion de documents scientifiques de niveau recherche, publiés ou non, émanant des établissements d'enseignement et de recherche français ou étrangers, des laboratoires publics ou privés. 


\section{Accepted Manuscript}

Title: Insight in $\mathrm{nAChR}$ subtype selectivity from AChBP crystal structures

Authors: Prakash Rucktooa, August B. Smit, Titia K. Sixma

PII: $\quad$ S0006-2952(09)00566-8

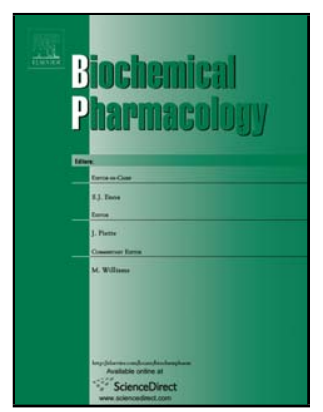

DOI: doi:10.1016/j.bcp.2009.06.098

Reference: BCP 10243

To appear in: $B C P$

Received date: 17-4-2009

Revised date: 19-6-2009

Accepted date: 22-6-2009

Please cite this article as: Rucktooa $\mathrm{P}$, Smit $\mathrm{AB}$, Sixma TK, Insight in $\mathrm{nAChR}$ subtype selectivity from AChBP crystal structures, Biochemical Pharmacology (2008), doi:10.1016/j.bcp.2009.06.098

This is a PDF file of an unedited manuscript that has been accepted for publication. As a service to our customers we are providing this early version of the manuscript. The manuscript will undergo copyediting, typesetting, and review of the resulting proof before it is published in its final form. Please note that during the production process errors may be discovered which could affect the content, and all legal disclaimers that apply to the journal pertain. 


\section{Title: Insight in nAChR subtype selectivity from AChBP crystal structures}

\section{Authors: Prakash Rucktooa' ${ }^{1}$ August B. Smit ${ }^{2}$, Titia K. Sixma1}

Affiliation:

${ }^{1}$ Division of Biochemistry and Center for Biomedical Genetics, Netherlands Cancer Institute, Plesmanlaan 121, 1066 CX Amsterdam, The Netherlands.

${ }^{2}$ Dept. of M olecular and Cellular Neurobiology, Center for Neurogenomics \& Cognitive Research, VU University, Amsterdam, The Netherlands 


\section{Running title: Ligand binding in AChBP structures}

Corresponding author: Titia K. Sixma 


\begin{abstract}
Nicotinic acetylcholine receptors (nAChRs) display a broad variety of subtypes, which in turn present a complex subcellular and regional expression pattern in the brain, as well as a specific pharmacological profile. The association of these nAChRs with different types of brain disease has turned them into interesting drug targets for the treatment of Alzheimer's disease or schizophrenia, or for anti-smoking compounds among others. In the same way, muscle-type nAChRs present at neuromuscular junctions are also being targeted by muscle relaxants. However, to date no high-resolution structural data is available on functional pentameric forms of membrane bound nicotinic receptors. Therefore, characterization of the selectivity profiles of different nicotinic receptor subtypes, enabling efficient drug design, is a serious issue. Over the last eight years various high resolution structures of acetylcholine binding protein $(\mathrm{AChBP})$, which is homologous to the extracellular ligand binding domain of the nicotinic acetylcholine receptor, have been obtained. AChBPs in complex with different ligands have provided detailed insight into the neurotransmitter binding site of nicotinic acetylcholine receptors. We present here the various efforts towards rationalizing subtype specificity in these receptors through the structural studies of acetylcholine binding proteinligand complexes.
\end{abstract}




\section{Introduction}

Cys-loop receptors (CLRs) are key to neuronal transmission processes both in the central and peripheral nervous systems. CLRs display a similar organization, as homo- or heteropentameric assemblies. Each protomer is composed of an extracellular N-terminal ligand binding domain (LBD) which displays a characteristic 12-13 amino acids long Cys-Cys loop, four C-terminal membrane spanning regions (M1-M4) and an intracellular region extending from M3 to M4 [1-3]. In vertebrates, the CLR family comprises the cation-selective nicotinic acetylcholine receptors (nAChRs), the 5- $\mathrm{HT}_{3}$ receptors, as well as the anion-selective glycine and $\mathrm{GABA}_{\mathrm{A} / \mathrm{C}}$ receptors. CLRs constitute interesting drug targets. nAChRs are drug targets in treating cognitive decline in Alzheimer's disease, certain forms of epilepsy or nicotine addiction [4]. Drugs directed towards $5 \mathrm{HT}_{3}$ receptors are used in case of emesis [5]. $\mathrm{GABA}_{\mathrm{A}}$ receptors are modulated by anesthetics or by compounds such as benzodiazepines to treat sleep or mood disturbances [6]. Glycine receptors, involved in sensory signal processing, are potential drug targets for relieving peripheral inflammatory pain or spastic conditions $[7,8]$. A common aspect of neurotransmitter binding is that it takes place at the subunit interfaces of the extracellular LBD whereas the transmembrane regions form the ion channel and constitute the ion selectivity filters.

nAChRs are prototypical members of the CLR family. They respond to the neurotransmitters acetylcholine and choline and are targeted by many non-endogenous neuroactive compounds like nicotine and snail and snake venom components, such as $\alpha$-Conotoxins and $\alpha$ Bungarotoxin, respectively [9]. nAChRs group into muscle-type and neuronal receptors. Muscle-type receptors are composed of four different subunits assembled with the $\left(\alpha_{1}\right)_{2} \beta_{1} \delta \gamma$ stoichiometry, and are found at the neuromuscular junctions in vertebrates as well as in the 
electric organs of some fish such as Torpedo marmorata. On the other hand, neuronal nAChRs are composed of $\alpha\left(\alpha_{2}-\alpha_{10}\right)$ and $\beta\left(\beta_{2}-\beta_{4}\right)$ subunits [10]. These subunits can assemble to form heteropentamers from combinations of $\alpha_{2}, \alpha_{3}, \alpha_{4}, \alpha_{6}$ with either $\beta_{2}$ or $\beta_{4}$, or with the addition of $\alpha_{5}$ and/or $\beta_{3}$ subunits. Whereas the extent of the pentamer diversity is not yet fully described, it is generally accepted that neuronal nAChRs contain at least two $\alpha$ subunits. The $\alpha_{7}-\alpha_{9}$ subunits can assemble as functional homopentameric receptors or as $\alpha$ subunit heteropentamers, and the $\alpha_{10}$ subunit forms heteropentamers with the $\alpha_{9}$ subunit [10]. Neuronal nAChRs are predominantly found on presynaptic nerve terminals where they modulate the release of neurotransmitters. The different subtypes of neuronal nAChRs display a complex expression profile in the brain. Receptor subtype stoichiometry and distribution together with their role in distinct behavioral responses are under investigation.

Given the complexity in structure and function of nAChRs several challenges remain. Specific targeting of a distinct nAChR subtype to treat neuronal disease is definitely an issue, which argues for in-depth structural investigation of the different ligand binding sites and how these data relate to receptor function.

Here, we aim at reviewing data from some of the detailed structural studies on AChBPs, which have contributed to shape our current understanding of ligand binding to nAChRs.

\section{Tools towards nAChR structure}

Many attempts have been made to gain structural data for integral membrane-bound nAChRs through the use of X-ray crystallography $[11,12]$. However, these experiments have been unfruitful so far, probably underlining the difficulty faced in obtaining sufficient amounts of integral membrane proteins in a homogeneous state that makes crystallization possible. Substantial progress however, was achieved through the cryo-electron microscopic analysis of 
the Torpedo marmorata muscle-type nAChR to a resolution of $4 \AA$ (PDB 2BG9) [13-15]. Whereas highly informative regarding the general architecture of nAChRs, the relatively low resolution of the solved structure led to a less well-defined view of the protomer-protomer interface constituting the receptor ligand binding site.

An important breakthrough in the understanding of CLR structure, in particular with respect to the ligand binding mechanisms, came from the characterization and structural determination of molluscan acetylcholine binding protein (AChBP) $[16,17]$. AChBP is secreted by molluscan glial cells and is homologous to the extracellular LBD of nAChRs, but lacking their transmembrane domain. AChBPs from Lymnaea stagnalis [17], Bulinus truncatus [18] and Aplysia californica [19] share only a 20-24\% sequence identity with nAChRs (Figure 1a) but display a striking structural resemblance with the Torpedo nAChR or mouse $\alpha 1 \mathrm{nAChR}$ protomer (Figure 1b). Nicotinic ligand binding to these AChBPs was assayed through different methods such as radioligand ( ${ }^{125} \mathrm{I}-\alpha$ Bungarotoxin) displacement, surface plasmon resonance [20-22], isothermal titration calorimetry [18] or intrinsic fluorescence quenching [19], and all the AChBPs were found to display a pharmacological profile close to that of the homopentameric $\alpha_{7} \mathrm{nAChR}[18,23]$.

Taken together, AChBP provides a good alternative to characterize ligand binding in nAChRs. Hence, CLR modeling strategies have heavily relied on the X-ray structures of AChBPs and their complexes together with the structure of the Torpedo nAChR [24-27]. The availability of the recently solved X-ray structure of the monomeric mouse $\alpha_{1}$ nAChR subunit in complex with $\alpha$-Bungarotoxin [28] indeed illustrates that AChBP constitutes a very good model for studying nAChRs, especially when considering the high degree of structural similarity between the $\alpha_{1}$ and AChBP structures; mouse $\alpha_{1} \mathrm{nAChR}$ subunit superposes to carbamylcholine-bound $L s \mathrm{AChBP}$ with an r.m.s. deviation of $1.29 \AA$ (Figure 1c) [29]. Owing 
to this high degree of structural identity, AChBP is also currently being used as a tool to search for subtype-specific nicotinic receptor ligands through a combined approach involving in silico docking, assaying $\mathrm{AChBP}$ binding to potential ligands, and the structural characterization of AChBP-ligand complexes by X-ray crystallography [30]. Such structural studies have also contributed to better understand the factors, which lead to the selectivity of neonicotinoid insecticides such as thiacloprid or imidacloprid for invertebrate nAChRs [31, 32].

Furthermore, the recently solved structures of the integral membrane proteins of the prokaryotic Erwinia chrysanthemi ELIC [33] and Gloeobacter violaceus GLIC [34, 35], displaying an architecture very close to that of the Torpedo nAChR also now provide a novel avenue for studying gating mechanisms from a structural standpoint.

\section{Canonical nAChR ligand binding site}

Ligand binding in CLRs occurs at the interface of the LBDs of two protomers. In nAChRs, this binding interface requires a mandatory $\alpha$ subunit, which contributes to the so-called principal face of the binding site whereas the adjacent subunit contributes to the complementary face. $\mathrm{AChBP}$ is a homopentamer consisting of five $\alpha$ subunits and hence displays five ligand-binding sites. Each ligand-binding site is built from loops originating from both faces of the protomer-protomer interface (Figure 2a). Residues from loops A, B and C from the principal face are well conserved (Figure 2c), whereas residues from complementary face loops D, E and F are more variable (Figure 2d). Altogether these residues make up an aromatic cage (Figure 2b), which can accommodate small molecule agonists such as nicotine, carbamylcholine and epibatidine. This aromatic cage is systematically involved in $\mathrm{AChBP} / \mathrm{nAChR}$-ligand interactions and this underscores the importance of cation- $\pi$ 
interactions in the stabilization of the nicotinic ligand cation $[36,37]$. Structures of AChBP complexes with these small agonists indeed reveal that the tertiary nitrogen of nicotine and epibatidine or the quaternary nitrogen of carbamylcholine interact with the negative charge generated by the $\pi$ electrons from the side chains of the residues making up the aromatic cage $[23,38]$. Polar nitrogens can also contribute to ligand stabilization in the binding pocket through a hydrogen bond with the main chain carbonyl group of the conserved tryptophan from the B loop. The nicotine-bound X-ray structure of AChBP [23] clearly shows that the carbonyl group of $L s \mathrm{AChBP}$ W143 is involved in a hydrogen bond with the nitrogen from the nicotine pyrrolidine moiety. This carbonyl group is stabilized by a hydrogen bond between the $\mathrm{NH}$ group from the peptide bond between residues 143 and 144 and the negatively charged D85 side chain. The analysis of several nAChR mutants further indicates that the negative charge from the conserved nAChR $\alpha$ subunit D89 plays a key role in receptor activation, affecting this event in an acetylcholine concentration dependent manner [39]. Other studies making use of unnatural amino acids and featuring an nAChR with an ester bond between residues 143 and 144 ( $L s$ AChBP numbering) lead to substantially different conclusions $[40,41]$. These studies suggest that a negative charge in position 89 of the nAChR $\alpha$ subunit is not essential in receptor function, but rather that D89 would be responsible in shaping the binding site of the receptor through an extensive hydrogen bond network, hence correctly positioning the conserved tryptophan residue. The loss of the planarity in the bond between residues 143 and 144 (LsAChBP numbering) through the substitution of the peptide bond by an ester [40, 41], however introduces a further uncharacterized variable in the picture, and hence leaves this issue unresolved. 


\section{Relating binding site variation to ligand affinity differences}

AChBP provides a good template for studying $\mathrm{nAChR}$ ligand binding. The soluble protein indeed comprises most of the nAChR binding site residues located on the principal face (Figure 1a). However, differences still exist in reported affinities between the actual receptors and binding proteins, which can be predominantly attributed to variations on the complementary face of the ligand-binding site. The structural characterization of L. stagnalis and B. truncatus AChBPs together with the characterization of their respective affinities for different ligands has indeed confirmed the importance of complementary face residues in the modulation of nAChR ligand binding affinities [18].

Nicotine binds to $L s \mathrm{AChBP}$ and $B t \mathrm{AChBP}$ with $k D$ values of $45 \mathrm{nM}$ and $8 \mathrm{nM}$, respectively. The structural comparison of these two AChBPs reveals that three complementary face binding site residues vary between the two proteins (Figure 3): LsAChBP R104, L112 and M114 are a valine, an isoleucine and a valine, respectively in BtAChBP [18]. Generating an LsAChBP triple mutant - R104V/L112I/M114V - shifts the affinity of LsAChBP for nicotine from $45 \mathrm{nM}$ to $12 \mathrm{nM}$. The same trend is also observed for d-tubocurarine binding to $L s \mathrm{AChBP}$ $(k D 42 \mathrm{nM})$ and $B t \mathrm{AChBP}(k D 20 \mathrm{nM})$ with the same $L s \mathrm{AChBP}$ triple mutant displaying a $k D$ of $20 \mathrm{nM}$.

Following these results, several efforts have been initiated, geared towards generating humanized versions of AChBP which would display a pharmacological profile close to that of the various $\mathrm{nAChR}$ subtypes.

However, whereas discrete variations in the AChBP ligand-binding site contribute to differences in the ligand binding affinity, they cannot be fully rationalized; assaying for acetylcholine binding with $L s \mathrm{AChBP}(k D 823 \mathrm{nM}), \operatorname{BtAChBP}(k D 153 \mathrm{nM})$ and the $L s \mathrm{AChBP}$ 
triple mutant $(k D>10000 \mathrm{nM})$ displays an inverse trend [18]. This result clearly implies that other residues located outside the binding site are relevant for nAChR ligand binding.

Further evidence pointing to the influence on the binding affinity of nAChRs of residues located outside of the ligand binding site comes from recent work comparing the muscle-type or neuronal $\alpha_{7}$ nAChRs to the neuronal $\alpha_{4} \beta_{2}$ nAChR [42]. Whereas these nAChRs contain the same conserved binding residues at their ligand binding protomer-protomer interface, it has been shown that a cation- $\pi$ interaction was absent in the nicotine activation of the muscle-type nAChR, suggesting that this interaction discriminates between high affinity neuronal receptors and low affinity muscle-type receptors [43]. The higher nicotine binding affinity of the $\alpha_{4} \beta_{2}$ nAChR compared to the $\alpha_{7}$ or muscle-type nAChRs was explained by mutagenesis studies. The authors suggest that the presence of a lysine at position 153, four residues away from the conserved binding site tryptophan in the $\alpha_{4} \beta_{2} \mathrm{nAChR}$, leads to the formation of a hydrogen bond between loops B and C, shaping the aromatic cage such that W149 is positioned to make close contact with nicotine [42]. Molecular dynamics simulations of the $\alpha_{7}$ nAChR suggest that the G153, also present in the muscle-type nAChR, would hamper the formation of a hydrogen bond between loops B and C, hence explaining the comparatively lower nicotine binding affinities displayed by these two receptors [42].

\section{Characterizing the plasticity of the nAChR ligand binding site}

Another strategy to uncover the different binding determinants responsible for subtype selectivity in nAChRs resides in the structural characterization of AChBP in complex with different nAChR targeting compounds (Figure 4a-h). 


\section{Using small molecules to assess selectivity determinants in the nAChR binding site}

\section{AChBP-Lobeline complex}

Nature provides for various small molecules such as toxins originating from plants, which display nAChR subtype selectivity. One such compound is lobeline, a natural alkaloid found in Lobelia inflata, which has been used as emetic, for respiratory stimulation as well as a smoking cessation aid [44]. Lobeline displays a 100-fold higher binding affinity for Aplysia californica AChBP than for LsAChBP, and acts as a partial agonist for the $\alpha_{3} \beta_{2}$ and $\alpha_{4} \beta_{2}$ subtype neuronal nAChRs. The structural characterization of the AcAChBP-lobeline complex provides an interesting view on the structural plasticity of the ligand binding site of $\mathrm{nAChRs}$ [38].

The structure shows that the ligand is stabilized through $\pi-\pi$ interactions between the central piperidine ring of lobeline and W145, which bring the ligand tertiary amine to hydrogen bonding distance with the carbonyl group of the conserved tryptophan residue. The ligand further interacts with complementary face residues from loop D in the apical region of the binding site (Figure 5a). More interestingly, the basal part of the ligand delineates a novel sub-pocket in the ligand-binding site which results from the flipping of the Y91 side chain originating from loop F (Figure 5b). This novel pocket is lined by three residues, i.e., K141, D195 and G143 (Figure 5c), which are highly conserved in AChBPs and $\alpha$-type nAChR protomers. The Y91 flip is stabilized by three polar interactions involving Q37, S167 and Y53 in AcAChBP.

\section{AChBP-Methyllycaconitine complex}

Methyllycaconitine (MLA) is another plant alkaloid originating from seeds of the Aconitum or Delphinium families. This compound is described as being highly selective for the $\alpha_{7} \mathrm{nAChR}$ 
subtype [45] and displaying comparable affinities for $L s$ and AcAChBPs [38]. The structure of AcAChBP in complex with MLA provides some indications on the selectivity determinants governing the binding of this ligand to nAChRs [38]. $\alpha_{7}$ nAChR subtype specificity arises from the N-phenyl succinimide moiety of MLA, linked via a flexible ester bond to the lycoctonine moiety which provides the tertiary amine stabilized by the conserved binding site tryptophan residue. The MLA N-phenyl succinimide moiety nests itself in a pocket located at the basal region of AcAChBP, lined by residues S92, M122, K141, Q184, D195 from the principal face and Q36 and S165 from the complementary face (Figure 6). The ester link carbonyl group is stabilized by Y53 from the complementary face loop D.

The AcAChBP-lobeline structure reveals that subtle side chain rearrangements as observed for Y91 can occur in the nAChR ligand binding site in order to accommodate a ligand. The AcAChBP-MLA structure provides another good example of novel, previously unpredicted, weakly conserved binding pockets potentially contributing to the selectivity of nAChRs.

\section{Investigating switches in nAChR selectivity between different ligands}

Venoms from cone snails provide interesting libraries of peptide toxins displaying a high affinity for voltage- or ligand-gated ion channels and have been successfully used as structural probes to characterize nAChRs $[9,46,47]$. $\alpha$-conotoxins, that specifically target nAChRs, display a consensus fold with a central helical region braced by two conserved disulphide bridges (Figure 7). This organization confers a rigid framework to the peptide. This rigidity together with the diversity in amino acid composition displayed by $\alpha$-conotoxins ensures their unique selectivity for different $\mathrm{nAChR}$ subtypes. These conotoxins have been classified into different families $(\alpha 3 / 5, \alpha 4 / 3, \alpha 4 / 6$ and $\alpha 4 / 7)$ based on the number of residues between the second and third cysteine residues and between the third and fourth cysteines [46]. 


\section{AChBP-PnIA complex}

PnIA is a member of the $\alpha 4 / 7 \alpha$-conotoxin family, selective for the $\alpha_{3} \beta_{2}$ nAChR subtype, with a 25-fold higher binding affinity for the $\alpha_{3} \beta_{2}$ subtype than for the homopentameric $\alpha_{7}$ receptor $[9,48,49]$. A point mutation in the toxin, resulting in $\operatorname{PnIA}(\mathrm{A} 10 \mathrm{~L})$ results in a complete switch in the selectivity of this toxin towards the $\alpha_{7}$ nAChR $[48,49]$. The PnIA(A10L D14K) variant displays a higher affinity towards $L s \mathrm{AChBP}$ and a 3-fold increased binding affinity for the chick $\alpha_{7} \mathrm{nAChR}$, but does not display a significant difference in binding with the human $\alpha_{7} \mathrm{nAChR}[20]$.

The co-crystal structure of AcAChBP with PnIA(A10L D14K) shows how a point mutation can bring about a drastic variation in the selectivity profile of a conotoxin. PnIA(A10L D14K) binding to AcAChBP occurs mainly through hydrophobic contacts with residues from both the principal and complementary faces of the binding site. The C-terminal region of the conotoxin variant is lodged in the apical region of the AChBP ligand-binding site, with the K14 residue protruding out of the binding site, hence explaining the lack of effect of the D14K mutant on AcAChBP. The L10 residue fits in a hydrophobic pocket composed of weakly conserved residues V146 from the principal face loop B and V106, M114 and I116 from the complementary face loop F (Figure 8).

Docking studies of PnIA variants further explained the gain in affinity of the A10L D14K mutant as compared to the A10L variant for LsAChBP. The K14 residue, which protrudes out of the binding site of $A c \mathrm{AChBP}$ can form a salt bridge with the LsAChBP complementary face E110 [20]. Docking studies performed on the $\alpha_{7} \mathrm{nAChR}$ further indicate that a series of nAChR specific residues could also affect ligand binding selectivity and affinity [20]. 


\section{AChBP-ImI complex}

ImI is a member of the $\alpha 4 / 3 \alpha$-conotoxin family, selective for the $\alpha_{7}$ and $\alpha_{3} \beta_{2}$ nAChRs [50]. This conotoxin further displays a 14.000-fold higher binding affinity for AcAChBP than for LsAChBP [38]. IMI-AcAChBP co-crystal structures $[22,38]$ show that ImI is stabilized in the binding site in the same orientation as $\operatorname{PnIA(A10L~D14K)~albeit~through~a~broader~range~of~}$ interactions [20]. Some of these interactions overlap, but the nature of most of the contacts varies considerably. The conotoxin R7 plays a key role in stabilizing the ligand through polar interactions with the principal face via a salt-bridge with loop C E195 as well as hydrogen bonds with Y91 (loop A), W145 (loop B) and I194 (loop C). This R7 also forms an intramolecular salt bridge with D5, hence giving rise to Van der Waals contacts with S144, V146 and Y147 from loop B. The ImI W10 is also a key residue in the ligand binding by inducing numerous contacts with the complementary face of the binding site, namely with R77, V106 and M114 from loop E as well as D75 and T108 (Figure 9), which are not observed in the AcAChBP-PnIA(A10L D14K) complex. The ImI W10 could be a key determinant in characterizing subtype selectivity among nAChRs. The substitution of V106 by an arginine present in $L s \mathrm{AChBP}$ is very likely to induce a steric clash with W10, hence the lower observed affinity of ImI for LsAChBP. High affinity ImI binding to the $\alpha_{3} \beta_{2}$ nAChR was found to rest on the presence of L119 in the nAChR [51]. This residue corresponds to I116 in $A c \mathrm{AChBP}$ but to a larger methionine in $L s \mathrm{AChBP}$, and could also be responsible for the differences in affinity observed between the two AChBPs. Based on the available ImIAChBP complex structures, the higher affinity of ImI for the $\alpha_{7}$ and $\alpha_{3} \beta_{2}$ nAChRs compared to the $\alpha_{9}$ and $\alpha_{3} \beta_{4}$ nAChRs can be rationalized. Indeed, the substitution of both Q55 and T108 by arginines or lysines in $\alpha_{9}$ and $\alpha_{3} \beta_{4}$ nAChRs would result in steric clashes with the ImI C3 and W10 respectively, hence contributing to lower observed affinities for these receptor subtypes [22]. 


\section{AChBP-TxIA complex}

TxIA is another $\alpha 4 / 7$ conotoxin isolated from the Conus textile snail. It was discovered when using AChBP as bait to fish out novel nAChR subtype selective conotoxins [21]. TxIA binds with high affinity to $L s \mathrm{AChBP}$, followed by the $\alpha_{3} \beta_{2}$ and $\alpha_{7}$ subtype receptors. This conotoxin presents only a 3-residue difference with the $\alpha 4 / 7$ type conotoxin PnIA, whereas displaying a 600-fold difference in binding affinity with $L s A C h B P$. The PnIA(A10L) variant improves affinity over PnIA by a 12.5 -fold factor for $L s$ AChBP, a 20 -fold factor for the $\alpha_{7}$ nAChR, but decreases affinity for the $\alpha_{3} \beta_{2}$ nAChR by a 10 -fold factor. Conversely, the TxIA(A10L) mutant did not show any affinity change for LsAChBP, but showed a 12-fold and 2-fold improvement in affinity towards the $\alpha_{7}$ and $\alpha_{3} \beta_{2}$ nAChRs, respectively. From these data, it was concluded that a long chain hydrophobic residue in position 9 or 10 of the conotoxin (I9 in TxIA, L10 in PnIA(A10L)) was required for high affinity binding to $L s A C h B P$ as well as to the $\alpha_{7}$ subtype nAChR, but not to the $\alpha_{3} \beta_{2}$ subtype. The substitution of the PnIA(A10L) L5 residue by the TxIA R5 improves $L s$ AChBP binding by 220 -fold and also improves $\alpha_{3} \beta_{2}$ subtype binding by 10 -fold. The PnIA(A10L L5R) variant does not show any difference in affinity for the $\alpha_{7}$ subtype nAChR. This dramatic increase in affinity of the PnIA(A10L L5R) variant for $L s \mathrm{AChBP}$ and the $\alpha_{3} \beta_{2}$ subtype highlights the importance of the R5 residue in the selective binding of the conotoxin to these two proteins (Figure 10).

The co-crystal structure of the AcAChBP-TxIA(A10L) variant [21] shows that the toxin is bound in a different orientation in the binding site as compared to $\operatorname{ImI}[22,38]$ or PnIA(A10L D14K) [20]. The $20^{\circ}$ downward tilt of the toxin in the binding site is correlated with a projection of the TxIA(A10L) R5 residue deep into the binding site principal face. This R5 makes a hydrogen bond with loop C Y185 and a salt bridge with loop C D195. The mutation of D195 into alanine or asparagine shows no effect on nicotine or PnIA(A10L D14K) binding 
affinities, however, displays a 30- to 50-fold reduction in binding affinity for both TxIA(A10L) and the PnIA(L5R A10L) variants. Voltage clamp analyses on oocytes expressing $\alpha_{7}$ or $\alpha_{3} \beta_{2}$ nAChR subtypes presenting equivalent mutations also concur with the binding results obtained with the AcAChBP mutants. A 200- to 500-fold decrease in activity is indeed observed for R5 containing toxins against the D197A- $\alpha_{3} \beta_{2}$. On the other hand, no effect was detected in the activity of R5 containing toxins against the D195A- $\alpha_{7}$. This could be explained by the fact that the TxIA(A10L) would adopt a PnIA(A10L D14K) like orientation in the $\alpha_{7}$ binding site, which would hamper the toxin R5- $\alpha_{7}$ D195 interaction. Furthermore, docking studies show that the $\alpha_{7}$ D195 is likely to form an internal salt bridge with K184, and would not be available for interaction with the TxIA(A10L) R5 residue.

\section{Neonicotinoids contribute to characterize species selectivity in}

\section{nAChRs}

Neonicotinoid insecticides such as imidacloprid effectively target insect nAChRs and display low affinity for mammalian nAChRs. Co-crystal structures of imidacloprid with LsAChBP [31] or with AcAChBP [32] have contributed to understand how such species selectivity arises.

Neonicotinoids are not protonated at physiological $p H$, but display a neutral heterocyclic ring as well as an electronegative tip constituted of a nitro or cyano functional group. These compounds hence deviate from cationic agonists such as nicotine. The crystal structures show that the ligand interacts with the backbone of amino acid residues in the ligand binding site, but also with residues from loops C, D and E (Figure 11a). Binding specificity most likely arises from the interaction between the ligand and loops C, D and E. 
LsAChBP M114, which corresponds to basic or polar residues in the $\alpha_{1}, \alpha_{2}$ or $\alpha_{3}$ Drosophila melanogaster nAChRs and to non-polar residues in vertebrate nAChR subunits, is positioned close to the nitroimine group of the ligand. This chemical group is likely to accept hydrogen bonds from residues equivalent to the $L s \mathrm{AChBP} \mathrm{M} 114$ in the insect $\alpha \mathrm{nAChR}$ subtypes [31].

The imidacloprid sensitivity of the chick $\alpha_{7} \mathrm{nAChR}$ is affected by mutation of the residue corresponding to the LsAChBP Q55 [52]. Mutating this chick $\alpha_{7}$ nAChR glutamine to arginine results in an increased sensitivity of the receptor to imidacloprid whereas mutating this residue to a glutamate induces a lower affinity for the ligand. Concordantly, insect $\beta$ $\mathrm{nAChR}$ subtypes display basic residues at the same position contrary to vertebrate $\beta \mathrm{nAChRs}$ subtypes. Only the human $\beta_{4} \mathrm{nAChR}$ subunit contains a lysine (K75) at that position. The potential sensitization caused by this residue is relieved by a glutamate two residues downstream, which might interfere with the interaction between the lysine and the nitro group of imidacloprid [31].

The analysis of the co-crystal structure of $L s \mathrm{AChBP}$ with imidacloprid also indicates that S186 in loop C makes hydrogen bonds with E163 and Y164 in loop F [31]. The mutation of the Drosophila $\alpha_{2}$ subunit proline (P243) to glutamate, equivalent to LsAChBP E163, was further found to decrease the sensitivity of the $\alpha_{2} \beta_{2} \mathrm{nAChR}$ to imidacloprid [53]. Conversely, mutating the human $\alpha_{4}$ subunit glutamate equivalent to $L s$ AChBP E163 to a proline leads to an increase in sensitivity of the $\alpha_{4} \beta_{2} \mathrm{nAChR}$ to imidacloprid [53]. Taking these data into account, it has been suggested that in heteromeric vertebrate nAChRs, the presence of acidic residues in the position equivalent to $L s \mathrm{AChBP}$ S186 would lead to electrostatic repulsion of acidic residues in the loop F on the complementary face. Such acidic residues are not found in the $\mathrm{C}$ loop of $\alpha$ subunits of heteromeric insect nAChRs, hence the increased binding efficiency of insecticide neonicotinoids to these receptors [31]. 
However, the structural characterization of $A c \mathrm{AChBP}$ in complex with imidacloprid provides an alternate view on how loop $\mathrm{C}$ residues participate in neonicotinoid binding in $\mathrm{nAChRs}$ [32]. This structure shows that loop $\mathrm{C}$ displays a higher degree of inward positioning towards the ligand binding site compared to LsAChBP (Figure 11b), in line with the higher imidacloprid sensitivity observed for $\operatorname{AcAChBP}(K i=19 \mathrm{nM})$ compared to $L s \operatorname{AChBP}(K i=$ 970nM) [54]. Furthermore in this structure AcAChBP S186 is not involved in hydrogen bonding with residues originating from the complementary face loop F but is involved in direct hydrogen bonding with the nitro group of imidacloprid (Figure 11b).

\section{Connecting ligand binding to Cys-loop motion in nAChRs}

Ligand binding to nAChRs can correlate with small side chain movements resulting in the binding site plasticity and this event is invariably accompanied by the motion of the $\mathrm{C}$ loop. The $\mathrm{C}$ loop displays various closure degrees onto the bound ligand depending on the chemical nature of the ligand. Hence, agonist binding to AChBP entails a closure of loop $\mathrm{C}$ whereas antagonist binding maintains it in an open state (Figure 12a). nAChR $\alpha$ subunits systematically house a pair of vicinal cysteines, linked through a disulphide bridge, at the tip of their C loop (Figure 1a). The C-loop closure induced by agonist binding brings these cysteines in close proximity to the ligand bound, hence contributing to ligand stabilization in the ligand-binding site. Recent work indicates that these vicinal cysteines do not interact with non-competitive binders co-crystallized with AChBP (Figure 12b), and show that their mutation to mimic non- $\alpha$ subunits does not affect the binding affinity to such non-competitive ligands [55].

Together with the characterization of binding affinities of various nAChR subtypes and of their respective mutants for different conotoxin variants, AChBP-conotoxin co-crystal 
structures have greatly helped us to better understand the key elements governing the subtype selectivity issue in nAChRs. Nevertheless, these different selectivity determinants have to be individually and precisely fished out through careful data analysis obtained from AChBPligand complexes. An exhaustive characterization of these determinants would ultimately need to rely on validation at the actual nicotinic receptor structures and complexes.

\section{Prokaryotic ligand gated ion channels: new perspectives into cys-loop receptor research}

Until recently it was thought that ligand gated ion channels (LGICs) were only expressed by multi-cellular eukaryotic organisms. However the availability of a large number of genomes has led to the discovery of novel ligand gated ion channels from bacterial sources [56]. This discovery has spurred much enthusiasm in the CLR field, and rapidly resulted in the electrophysiological characterization of the Gloeobacter violaceus GLIC, one of the members of this new protein family, showing that the channel was activated by protons [57]. These results were quickly followed by the structural characterization of full length Erwinia chrysanthemi ELIC, an orthologue of GLIC, in a closed state [33], and by those of full length GLIC in an open state $[34,35]$. These structural data indicate that the nAChR architecture is mostly conserved in both ELIC and GLIC (Figure 13a).

Despite displaying a low level of sequence conservation, the comparison of the structures of ELIC and GLIC provides insight into the gating mechanism in CLRs [58]. The open state in GLIC correlates with a concerted twist motion compared to ELIC in its closed state. GLIC hence displays an anti-clockwise rotation of its ECD, accompanied by a clockwise rotation of its transmembrane region relative to the ELIC structure. In the ECD, a rotation of $8^{\circ}$ is also observed for the core of the $\beta$-sandwich around an axis perpendicular to the inner sheet of the $\beta$-sandwich [34]. 
Such global conformational changes are absent in AChBP. Therefore, it has been suggested that this protein is stabilized in a fixed conformation and most likely resembles a nAChR in its desensitized state [59].

Despite the fact that a ligand as small as a proton could potentially activate ELIC [33], this protein displays an intriguing protomer-protomer interface containing aromatic residues which are reminiscent of the aromatic cage observed in the AChBP ligand binding site (Figure 13b). The proton-gated GLIC, on the other hand does not present aromatic side chains at the protomer-protomer interface analogous to those present in the AChBP binding site.

Current research directions in the prokaryotic LGIC field include the screening for novel potential ELIC or GLIC agonists. These in turn will lead to a better understanding of the coupling mechanism between ligand binding and channel gating. 


\section{Figures}

Figure 1a: 3D-coffee based sequence alignment of Aplysia, Lymnea and Bulinus AChBPs with the mouse $\alpha_{1}$, human $\alpha_{7}, \alpha_{4}$ and $\beta_{2} \mathrm{nAChR}$ subunits, taking into account available structural information from the $A c, L s$ and BtAChBPs and mouse $\alpha_{1}$ subunit. Loops A-F, contributing to the binding site, are highlighted in blue blocks for principal site residues and beige blocks for complementary site residues. Principal face residues involved in agonist binding are colored red, whereas those from the complementary face are colored yellow.

Figure 1b: Superposition of Aplysia (PDB: 2BR7), Lymnaea (PDB: 1UX2) and Bulinus (PDB: 2BJ0) AChBPs with the Torpedo a muscle type nAChR subunit (PDB: 2BG9).

Figure 1c: Superposition of Aplysia (PDB: 2BR7), Lymnaea (PDB: 1UX2) and Bulinus (PDB: 2BJ0) AChBPs with the mouse $\alpha_{1}$ nAChR subunit (PDB: 2QC1).

Figure 2a-b: Lymnaea stagnalis AChBP protomer-protomer interface making up the ligand binding site, with loops contributing to the binding interface highlighted (a). Residues involved in contacts with nicotine in $L s \mathrm{AChBP}$ are shown in detail in a blown-up view (b).

Figure 2c-d: Superposition of the Ac (PDB: 2BR7), Ls (PDB: 1UX2) and BtAChBP (PDB: 2BJ0) residues contributing to the principal (c) or complementary (d) face of the ligandbinding site. Principal face residues are highly conserved while the complementary face displays more variability.

Figure 3: Superposition of structures of nicotine-bound LsAChBP (grey) (PDB: 1UW6) with CAPS-containing BtAChBP (orange) (PDB: 2BJ0), to rationalize the binding differences between $L s$ and BtAChBPs for nicotine. The principal face of the binding site has been removed revealing residues at positions 104,112 and 114 located on the complementary face 
of $L s$ and BtAChBPs. The concomitant mutation of the three $L s$ AChBP residues depicted in grey to their $B t$ counterparts (R104V/L112I/M114V) brings about an approximately 8-fold gain in affinity of $L s \mathrm{AChBP}$ for nicotine.

Figure 4a-h: Protomer-protomer interfaces of different AChBP-ligand complexes illustrate how different ligands contribute to characterize subtleties of the nAChR binding site. Small molecule agonists, nicotine (PDB: 1UW6), carbamylcholine (PDB: 1UV6) and epibatidine (PDB: 2BYQ) are localized in the aromatic cage (a-c), whereas the partial agonist lobeline (PDB: 2BYS) (d) or the antagonist methyllycaconitine (PDB: 2BYR) (e) explore novel subpockets in the AChBP binding site. Discrete interactions between specific residues from the larger peptide conotoxins ImI (PDB: 2CT9) (f), PnIA(A10L D14K) (PDB: 2BR8) (g) or TxIA(A10L) (PDB: 2UZ6) (h) with residues in the AChBP binding site contribute to the characterization of selectivity switches in nAChRs. The protomer contributing to the principal face of the binding site is colored silicon whereas the protomer contributing to the complementary face is colored grey. Ligands are shown in green and the ligand surface (blue), is shown in transparency. The same color scheme is adopted in following figures.

Figure 5a-c: (a) Lobeline binding in the AcAChBP binding site (PDB: 2BYS) defines apical and basal sub-pockets. (b) Superposition of Y91 of AcAChBP bound to epibatidine (2BYQ) (blue) or to lobeline (silicon) shows that side-chain rearrangement is required for lobeline binding to take place. (c) A novel sub-pocket, lined by Y91, K141, G143 and D195, is identified in the basal region of AChBP.

Figure 6: The co-crystal structure of $A c \mathrm{AChBP}$ with methyllycaconitine (MLA) (PDB: 2BYR) reveals a potential $\alpha_{7}$ nAChR subtype selectivity determinant mapped by the N-phenyl succinimide moiety of MLA nested in an AChBP pocket lined by residues originating from 
both the principal and complementary faces. The N-phenyl succinimide moiety of MLA is outlined by dashes.

Figure 7: Ribbon representation of $\alpha$-conotoxins PnIA(A10L D14K), ImI and TxIA(A10L). The conotoxins display rigid structures with a central helical region maintained by two disulphide bridges.

Figure 8: The co-crystal structure of AcAChBP with PnIA(A10L D14K) (PDB: 2BR8) illustrates how an alanine to leucine mutation in position 10 of the conotoxin brings about a complete switch in its selectivity profile from $\alpha_{3} \beta_{2}$ to the $\alpha_{7}$. A close-up view on conotoxin L10 residue shows that it is nested in a pocket lined by poorly conserved residues, which might lead to $\alpha_{7} \mathrm{nAChR}$ selectivity.

Figure 9: ImI binding to $A c \mathrm{AChBP}$ helps in understanding the differences in affinity observed in the binding of the conotoxin to $A c$ and $L s \mathrm{AChBP}$ as well as to different nAChRs. The X-ray structure of ImI-AcAChBP complex (PDB: 2CT9) indicates that the residues lining the $W 10$ pocket are very likely to contribute to binding selectivity in nAChRs.

Figure 10: The TxIA(A10L) R5 residue is a key selectivity probe for $\mathrm{nAChRs}$, allowing the discrimination between the $\alpha_{7}$ and $\alpha_{3} \beta_{2}$ receptor subtypes (PDB: 2UZ6).

Figure 11a-b: Imidacloprid in complex with $L s \mathrm{AChBP}$ (PDB: 2ZJU) indicates that the nature of the residues in positions equivalent to the $L s \mathrm{AChBP}$ Q55 or M114 is a key determinant for the specificity of insecticide neonicotinoids for insect nAChRs (a). The superposition of the structures of imidacloprid-bound $L s \mathrm{AChBP}$ (principal face in silicon and complementary face in grey) with imidacloprid-bound AcAChBP (PDB: 3C79) (principal face in blue and complementary face in orange) depicts two different modes of involvement of the Cloop in 
insecticide neonicotinoid binding. LsAChBP S186 contacts Y164 and E165 from loop F, whereas AcAChBP S186 makes a hydrogen bond with the nitro group of imidacloprid (b).

Figure 12a-b: Imidacloprid in complex with $L s \mathrm{AChBP}$ (PDB: 2ZJU) indicates that the nature of the residues in positions equivalent to the $L s \mathrm{AChBP}$ Q55 or M114 is a key determinant for the specificity of insecticide neonicotinoids for insect nAChRs (a). The superposition of the structures of imidacloprid-bound $L s \mathrm{AChBP}$ (principal face in silicon and complementary face in grey) with imidacloprid-bound $A c \mathrm{AChBP}$ (PDB: 3C79) (principal face in blue and complementary face in orange) depicts two different modes of involvement of the C loop in insecticide neonicotinoid binding. LsAChBP S186 contacts Y164 and E165 from loop F, whereas AcAChBP S186 makes a hydrogen bond with the nitro group of imidacloprid (b).

Figure 13a-b: View of the $\mathrm{C}$ loop following the superposition of $A c \mathrm{AChBP}$ in complex with TxIA(A10L) in red (PDB: 2UZ6), galanthamine in blue (PDB: 2PH9) or epibatidine in orange (PDB: 2BYQ), with an apo structure of $A c \mathrm{AChBP}$ in silicon (PDB: 2W8E), shown with an epibatidine molecule positioned in the ligand binding site. Various degrees of $\mathrm{C}$ loop motion are observed depending on the nature of the bound ligand (a). The disulphide bridged vicinal cysteines at the tip of the $\mathrm{C}$ loop do not contact the non-competitive ligand galanthamine (b).

Figure 13a-b: The superposition of the structures of the muscle-type T. marmorata nAChR (PDB: 2BG9) with GLIC (PDB: 3EAM) and ELIC (PDB: 2VL0) illustrates a highly conserved architecture among the three proteins with the notable absence of an intracytoplasmic loop in the prokaryotic receptors (a). The ELIC protomer-protomer interface intriguingly displays aromatic residues, which superpose with those from the $L s \mathrm{AChBP}$ binding site shown in transparency in blue (b). 


\section{Acknowledgements}

The authors wish to acknowledge financial support from the EU FP7 Neurocypres program. PR is supported by a long-term fellowship from the European Molecular Biology Organization. 


\section{References}

[1] Sine SM, Engel AG. Recent advances in Cys-loop receptor structure and function. Nature 2006;440:448-55.

[2] Corringer PJ, Le Novere N, Changeux JP. Nicotinic receptors at the amino acid level. Annual review of pharmacology and toxicology 2000;40:431-58.

[3] Karlin A. Emerging structure of the nicotinic acetylcholine receptors. Nature reviews 2002;3:102-14.

[4] Arneric SP, Holladay M, Williams M. Neuronal nicotinic receptors: a perspective on two decades of drug discovery research. Biochemical pharmacology 2007;74:1092-101.

[5] Thompson AJ, Lummis SC. The 5-HT3 receptor as a therapeutic target. Expert opinion on therapeutic targets 2007;11:527-40.

[6] Foster AC, Kemp JA. Glutamate- and GABA-based CNS therapeutics. Current opinion in pharmacology 2006;6:7-17.

[7] Lynch JW. Native glycine receptor subtypes and their physiological roles. Neuropharmacology 2009;56:303-9.

[8] Betz H, Laube B. Glycine receptors: recent insights into their structural organization and functional diversity. Journal of neurochemistry 2006;97:1600-10.

[9] Tsetlin VI, Hucho F. Snake and snail toxins acting on nicotinic acetylcholine receptors: fundamental aspects and medical applications. FEBS letters 2004;557:9-13.

[10] M cGehee DS. M olecular diversity of neuronal nicotinic acetylcholine receptors. Annals of the New York Academy of Sciences 1999;868:565-77.

[11] Paas Y, Cartaud J, Recouvreur M, Grailhe R, Dufresne V, Pebay-Peyroula E, et al. Electron microscopic evidence for nucleation and growth of 3D acetylcholine receptor microcrystals in structured lipid-detergent matrices. Proceedings of the National Academy of Sciences of the United States of America 2003;100:11309-14.

[12] Ross MJ, Klymkowsky MW, Agard DA, Stroud RM. Structural studies of a membrane-bound acetylcholine receptor from Torpedo californica. Journal of molecular biology 1977;116:63559.

[13] Unwin N. Acetylcholine receptor channel imaged in the open state. Nature 1995;373:37-43.

[14] Unwin N. The nicotinic acetylcholine receptor of the Torpedo electric ray. Journal of structural biology 1998;121:181-90.

[15] Unwin N. Refined structure of the nicotinic acetylcholine receptor at 4A resolution. Journal of molecular biology 2005;346:967-89.

[16] Brejc K, van Dijk WJ, Klaassen RV, Schuurmans M, van Der Oost J, Smit AB, et al. Crystal structure of an ACh-binding protein reveals the ligand-binding domain of nicotinic receptors. Nature 2001;411:269-76.

[17] Smit AB, Syed NI, Schaap D, van Minnen J, Klumperman J, Kits KS, et al. A glia-derived acetylcholine-binding protein that modulates synaptic transmission. Nature 2001;411:261-8.

[18] Celie PH, Klaassen RV, van Rossum-Fikkert SE, van Elk R, van Nierop P, Smit AB, et al. Crystal structure of acetylcholine-binding protein from Bulinus truncatus reveals the conserved structural scaffold and sites of variation in nicotinic acetylcholine receptors. The Journal of biological chemistry 2005;280:26457-66.

[19] Hansen SB, Radic Z, Talley TT, Molles BE, Deerinck T, Tsigelny I, et al. Tryptophan fluorescence reveals conformational changes in the acetylcholine binding protein. The Journal of biological chemistry 2002;277:41299-302.

[20] Celie PH, Kasheverov IE, Mordvintsev DY, Hogg RC, van Nierop P, van Elk R, et al. Crystal structure of nicotinic acetylcholine receptor homolog AChBP in complex with an alphaconotoxin PnIA variant. Nature structural \& molecular biology 2005;12:582-8. 
[21] Dutertre S, Ulens C, Buttner R, Fish A, van Elk R, Kendel Y, et al. AChBP-targeted alphaconotoxin correlates distinct binding orientations with nAChR subtype selectivity. The EMBO journal 2007;26:3858-67.

[22] Ulens C, Hogg RC, Celie PH, Bertrand D, Tsetlin V, Smit AB, et al. Structural determinants of selective alpha-conotoxin binding to a nicotinic acetylcholine receptor homolog AChBP. Proceedings of the National Academy of Sciences of the United States of America 2006;103:3615-20.

[23] Celie PH, van Rossum-Fikkert SE, van Dijk WJ, Brejc K, Smit AB, Sixma TK. Nicotine and carbamylcholine binding to nicotinic acetylcholine receptors as studied in AChBP crystal structures. Neuron 2004;41:907-14.

[24] Cromer BA, Morton CJ, Parker MW. Anxiety over GABA(A) receptor structure relieved by AChBP. Trends in biochemical sciences 2002;27:280-7.

[25] Le Novere N, Grutter T, Changeux JP. Models of the extracellular domain of the nicotinic receptors and of agonist- and $\mathrm{Ca} 2+$-binding sites. Proceedings of the National Academy of Sciences of the United States of America 2002;99:3210-5.

[26] Reeves DC, Sayed MF, Chau PL, Price KL, Lummis SC. Prediction of 5-HT3 receptor agonistbinding residues using homology modeling. Biophysical journal 2003;84:2338-44.

[27] Speranskiy K, Cascio M, Kurnikova M. Homology modeling and molecular dynamics simulations of the glycine receptor ligand binding domain. Proteins 2007;67:950-60.

[28] Dellisanti CD, Yao Y, Stroud JC, Wang ZZ, Chen L. Crystal structure of the extracellular domain of nAChR alpha1 bound to alpha-bungarotoxin at $1.94 \mathrm{~A}$ resolution. Nature neuroscience 2007;10:953-62.

[29] Sixma TK. Nicotinic receptor structure emerging slowly. Nature neuroscience 2007;10:937-8.

[30] Ulens C, Akdemir A, Jongejan A, van Elk R, Bertrand S, Perrakis A, et al. Use of Acetylcholine Binding Protein in the Search for Novel alpha7 Nicotinic Receptor Ligands. In Silico Docking, Pharmacological Screening, and X-ray Analysis (dagger). Journal of medicinal chemistry 2009.

[31] Ihara M, Okajima T, Yamashita A, Oda T, Hirata K, Nishiwaki H, et al. Crystal structures of Lymnaea stagnalis AChBP in complex with neonicotinoid insecticides imidacloprid and clothianidin. Invert Neurosci 2008;8:71-81.

[32] Talley $T$, Harel M, Hibbs RE, Radic Z, Tomizawa M, Casida JE, et al. Atomic interactions of neonicotinoid agonists with AChBP: molecular recognition of the distinctive electronegative pharmacophore. Proceedings of the National Academy of Sciences of the United States of America 2008;105:7606-11.

[33] Hilf RJ, Dutzler R. X-ray structure of a prokaryotic pentameric ligand-gated ion channel. Nature 2008;452:375-9.

[34] Bocquet N, Nury H, Baaden M, Le Poupon C, Changeux JP, Delarue M, et al. X-ray structure of a pentameric ligand-gated ion channel in an apparently open conformation. Nature 2009;457:111-4.

[35] Hilf RJ, Dutzler R. Structure of a potentially open state of a proton-activated pentameric ligand-gated ion channel. Nature 2009;457:115-8.

[36] Lester HA, Dibas MI, Dahan DS, Leite JF, Dougherty DA. Cys-loop receptors: new twists and turns. Trends in neurosciences 2004;27:329-36.

[37] Zhong W, Gallivan JP, Zhang Y, Li L, Lester HA, Dougherty DA. From ab initio quantum mechanics to molecular neurobiology: a cation-pi binding site in the nicotinic receptor. Proceedings of the National Academy of Sciences of the United States of America 1998;95:12088-93.

[38] Hansen SB, Sulzenbacher G, Huxford T, M archot P, Taylor P, Bourne Y. Structures of Aplysia $\mathrm{AChBP}$ complexes with nicotinic agonists and antagonists reveal distinctive binding interfaces and conformations. The EM BO journal 2005;24:3635-46. 
[39] Lee WY, Sine SM. Invariant aspartic Acid in muscle nicotinic receptor contributes selectively to the kinetics of agonist binding. The Journal of general physiology 2004;124:555-67.

[40] Cashin AL, Petersson EJ, Lester HA, Dougherty DA. Using physical chemistry to differentiate nicotinic from cholinergic agonists at the nicotinic acetylcholine receptor. Journal of the American Chemical Society 2005;127:350-6.

[41] Cashin AL, Torrice M M , M cM enimen KA, Lester HA, Dougherty DA. Chemical-scale studies on the role of a conserved aspartate in preorganizing the agonist binding site of the nicotinic acetylcholine receptor. Biochemistry 2007;46:630-9.

[42] Xiu X, Puskar NL, Shanata JA, Lester HA, Dougherty DA. Nicotine binding to brain receptors requires a strong cation-pi interaction. Nature 2009;458:534-7.

[43] Beene DL, Brandt GS, Zhong W, Zacharias NM, Lester HA, Dougherty DA. Cation-pi interactions in ligand recognition by serotonergic (5-HT3A) and nicotinic acetylcholine receptors: the anomalous binding properties of nicotine. Biochemistry 2002;41:10262-9.

[44] Dwoskin LP, Crooks PA. A novel mechanism of action and potential use for lobeline as a treatment for psychostimulant abuse. Biochemical pharmacology 2002;63:89-98.

[45] Ward JM, Cockcroft VB, Lunt GG, Smillie FS, Wonnacott S. Methyllycaconitine: a selective probe for neuronal alpha-bungarotoxin binding sites. FEBS letters 1990;270:45-8.

[46] Olivera BM. Conus peptides: biodiversity-based discovery and exogenomics. The Journal of biological chemistry 2006;281:31173-7.

[47] Lewis RJ, Garcia ML. Therapeutic potential of venom peptides. Nat Rev Drug Discov 2003;2:790-802.

[48] Hogg RC, Miranda LP, Craik DJ, Lewis RJ, Alewood PF, Adams DJ. Single amino acid substitutions in alpha-conotoxin PnIA shift selectivity for subtypes of the mammalian neuronal nicotinic acetylcholine receptor. The Journal of biological chemistry 1999;274:36559-64.

[49] Luo S, Nguyen TA, Cartier GE, Olivera BM, Yoshikami D, Mclntosh JM. Single-residue alteration in alpha-conotoxin PnIA switches its nAChR subtype selectivity. Biochemistry 1999;38:14542-8.

[50] Ellison M, Gao F, Wang HL, Sine SM, M clntosh JM, Olivera BM. Alpha-conotoxins Iml and ImII target distinct regions of the human alpha7 nicotinic acetylcholine receptor and distinguish human nicotinic receptor subtypes. Biochemistry 2004;43:16019-26.

[51] Dutertre S, Nicke A, Lewis RJ. Beta2 subunit contribution to 4/7 alpha-conotoxin binding to the nicotinic acetylcholine receptor. The Journal of biological chemistry 2005;280:30460-8.

[52] Shimomura M, Okuda H, M atsuda K, Komai K, Akamatsu M, Sattelle DB. Effects of mutations of a glutamine residue in loop $D$ of the alpha7 nicotinic acetylcholine receptor on agonist profiles for neonicotinoid insecticides and related ligands. British journal of pharmacology 2002;137:162-9.

[53] Shimomura M, Yokota M, Matsuda K, Sattelle DB, Komai K. Roles of loop C and the loop B-C interval of the nicotinic receptor alpha subunit in its selective interactions with imidacloprid in insects. Neurosci Lett 2004;363:195-8.

[54] Tomizawa M, Casida JE. Molecular recognition of neonicotinoid insecticides: the determinants of life or death. Accounts of chemical research 2009;42:260-9.

[55] Hansen SB, Taylor P. Galanthamine and non-competitive inhibitor binding to ACh-binding protein: evidence for a binding site on non-alpha-subunit interfaces of heteromeric neuronal nicotinic receptors. Journal of molecular biology 2007;369:895-901.

[56] Tasneem A, Iyer LM, Jakobsson E, Aravind L. Identification of the prokaryotic ligand-gated ion channels and their implications for the mechanisms and origins of animal Cys-loop ion channels. Genome biology 2005;6:R4. 
[57] Bocquet N, Prado de Carvalho L, Cartaud J, Neyton J, Le Poupon C, Taly A, et al. A prokaryotic proton-gated ion channel from the nicotinic acetylcholine receptor family. Nature 2007;445:116-9.

[58] Cederholm JM, Schofield PR, Lewis TM. Gating mechanisms in Cys-loop receptors. Eur Biophys J 2009.

[59] Sixma TK, Smit AB. Acetylcholine binding protein (AChBP): a secreted glial protein that provides a high-resolution model for the extracellular domain of pentameric ligand-gated ion channels. Annual review of biophysics and biomolecular structure 2003;32:311-34.

[60] Hansen SB, Talley $\Pi$, Radic Z, Taylor P. Structural and ligand recognition characteristics of an acetylcholine-binding protein from Aplysia californica. The Journal of biological chemistry 2004;279:24197-202. 
Table 1: Binding affinities of ligands to AChBP

\begin{tabular}{|c|c|c|c|c|c|}
\hline \multirow[b]{2}{*}{ Ligand } & \multicolumn{2}{|c|}{$K D(\mathrm{nM})$} & \multicolumn{2}{|c|}{ PDB code } & \multirow[b]{2}{*}{ Reference } \\
\hline & $A c \mathrm{AChBP}$ & LsAChBP & $A c \mathrm{AChBP}$ & LsAChBP & \\
\hline Nicotine & 245 & 45 & & 1UW6 & {$[23],[60]$} \\
\hline Carbamylcholine & - & 7500 & & 1UV6 & [23] \\
\hline Epibatidine & 14 & 0.2 & 2BYQ & & {$[38],[60]$} \\
\hline Lobeline & 0.5 & 130 & 2BYS & & [38] \\
\hline Methyllycaconitine & 2.8 & 0.4 & 2BYR & & {$[38],[60]$} \\
\hline $\operatorname{ImI}$ & 33 & 4000 & 2СТ9,2ВYР & & {$[20],[38]$} \\
\hline PnIA(A10L) & 37 & 85 & & & {$[20]$} \\
\hline $\operatorname{PnIA(A10L~D14K)~}$ & 33 & 28 & 2BR8 & & {$[20]$} \\
\hline TxIA & - & $1.7^{*}$ & & & [21] \\
\hline TxIA(A10L) & - & $1.1^{*}$ & 2UZ6 & & [21] \\
\hline Imidacloprid & $19 *$ & $970^{*}$ & $3 C 79$ & 2ZJU & [31], [32], [54] \\
\hline Galanthamine & 16000 & 3000 & 2PH9 & & [55] \\
\hline
\end{tabular}

* $I C_{50}$ values. 
(a)

ACACheP

ZSAChBP

DeAchap

Mal

fax?

Pox

IIS2

Acrehes

zerchap

DeAchap

Mat

Ha?

for 4

IIa 2

ACAChaJ

ZeAChBi

DeAchap

Mal

Hat

Poos

M2

Acrehar

IsAChBi

Deschap

Mat 1

Ha?

for 4

H92 $\alpha 1$

0200000200

B1

D

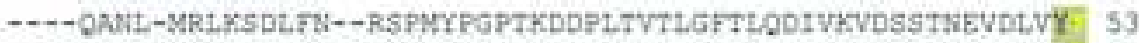
-.-LSLDAADILYNIRQTSRPDVIFTO-RDRPVAVSVSLKEINII.EVNEITNEVDVVE 55 ---01AK--TLLNOITG--ESDVIPLS-WWTPLAVSLNFKLMIVEADTEKDQVEVVL 51

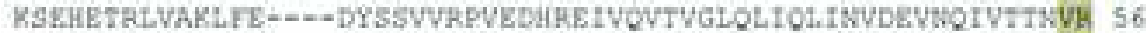

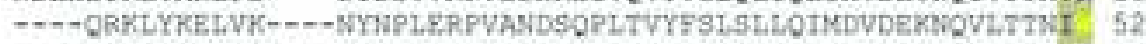

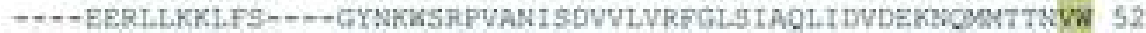
-.--EERLVEHLLDE--SRYNKLIRPATHGSELVTVOLNVLhOLISVHEREOMTTWV S4 $\stackrel{B 2}{\rightarrow 1} \quad 2^{2} \quad \stackrel{B 3}{\longrightarrow 2} \quad \stackrel{B 4}{\rightarrow} A \quad \stackrel{B 5}{\rightarrow} \stackrel{B 5}{\longrightarrow} \mathbf{E}$

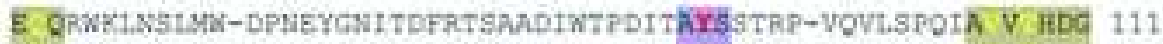

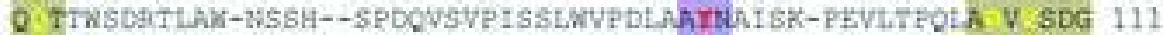
7. ASKKVPYYSSLLSSS--3LDOVSLPUSKOWTPDLSEXKIAR-PBLLSADRV V KDG 10 a LXOCWVDYWLKA-NPDDYGGVKXIHIPSEKIWRPDVVIXWNADGDFATVXYTKVIA.DYTG 115 E RSXTDHYLOW-WVSEYPGVRTVRFPDOQIWKPDILIYNSADERFDATFHTNV V SSO 111

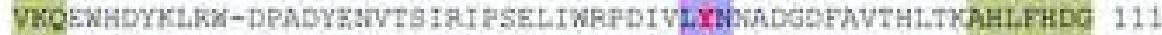
E QENEDYRLIU-KPEEFDSAKKVRLESKHIWLDDVVLYLIADGMYKVSFYSWA V YDG 113 $\stackrel{\beta 6}{\longrightarrow} \stackrel{\beta 6^{\circ}}{\longrightarrow} \quad \stackrel{\beta 7}{\longrightarrow} \mathrm{B} \stackrel{\beta 8}{\longrightarrow} \stackrel{\mathrm{F}}{\longrightarrow}$

SV E PAORLSFNCDPTGVD-SEECVTCAVKECSHVYSGFEIDLKTDTD-OVDLSSYX-A 168 EV $X$ PSIHORRSCDVSGVD-ZESGATCAIKTGSWTHHSGEI SVDPTTE-NSDDSEYESO 169 SV Y PSQRVRYTCDLINVD-TEPGATCRIKVGSHTHDNKQEALITGEEGVVNIAEYP-D 166 HITWTPPAIVKSYCEITVTHEDFDEONCSNKLGTWTYDGSVVALNPESD-OPDSSEEM-E 173 HC $X$ PPGIFKSSCYIDVFWFPFDVOHCKL KFGSWSYGGWSLDLON--0-EADISGYI-P 16? RVCWTPPAIYKSSCSIDVTFFPFDOONCTNKEOSWTYDKAKIDLVMMHS-RVDOLDFW-E 169

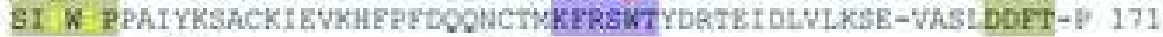

$\beta 9$

C

B10

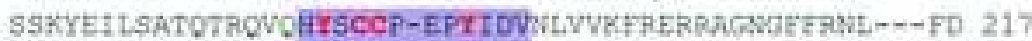

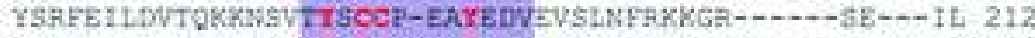
SPKEDLLSATQSLNRKKYSCCE-ERYDOIEITYAFRK-..............K 203

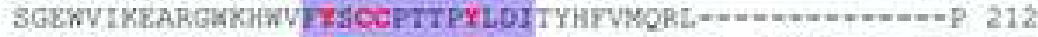
NGEWDLVGI PGKRSERFYECK-EPXPDVTFTVTKRRRT--LYYCLALLTPCV 217 SGEWVIVDAVGTYNTRKYZCCA-EIYPDITYAFVIGRL,P-LLFYTINLI1PCL 219

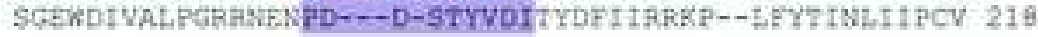

(b)

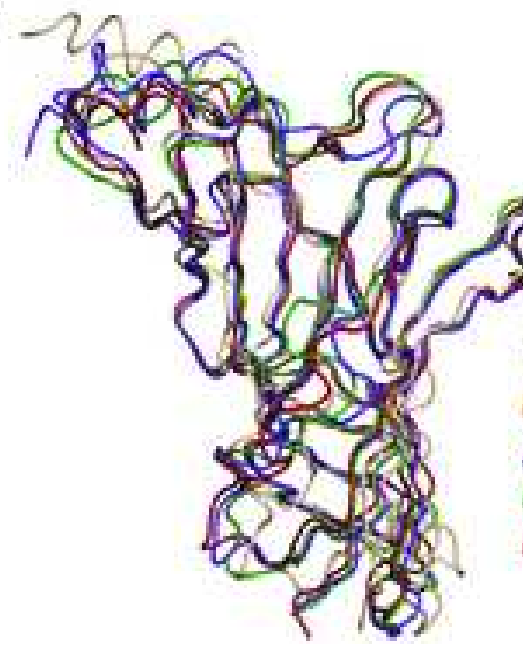

(c)

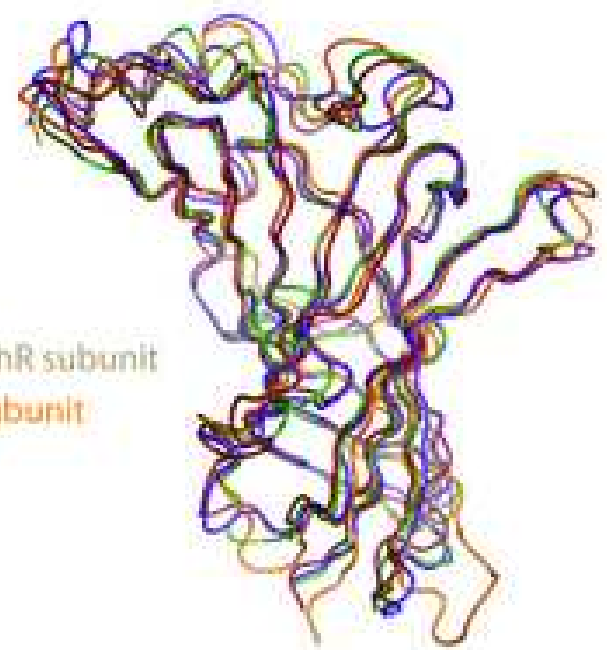

Torpedo o - Y $\cap$ ACChR subunit Mouse ul nAChR suburit AcAChBP BtAChEP LSAChBP 
(a)

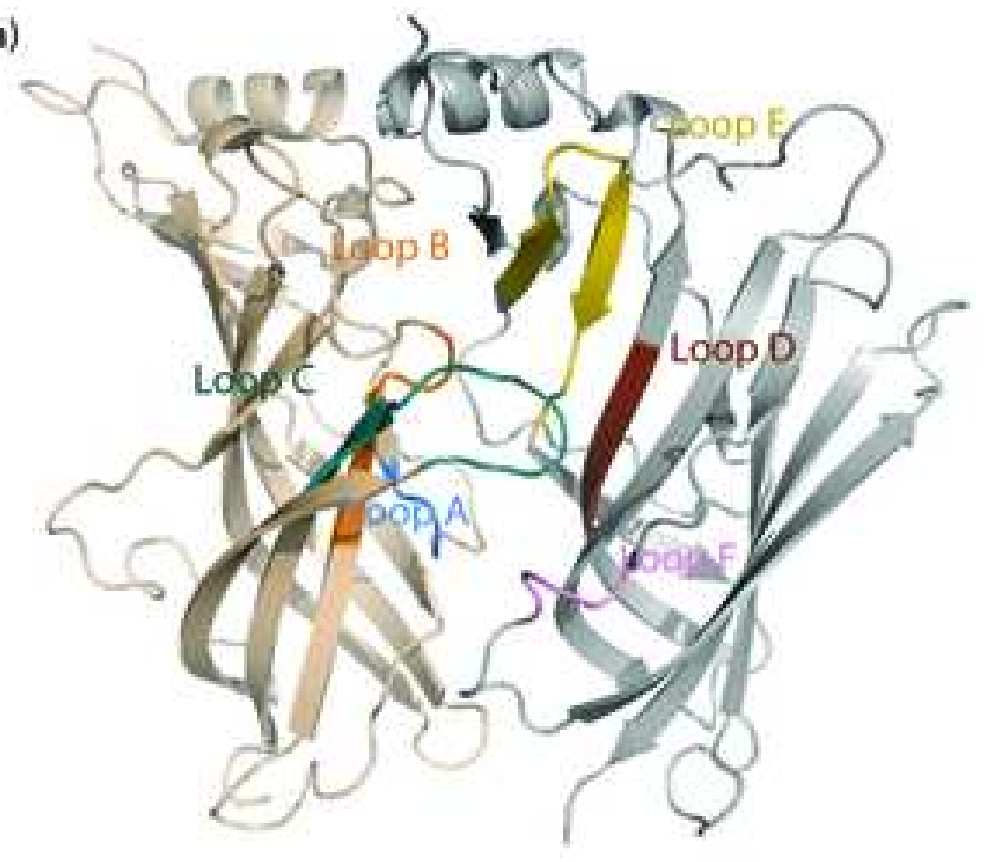

(c)

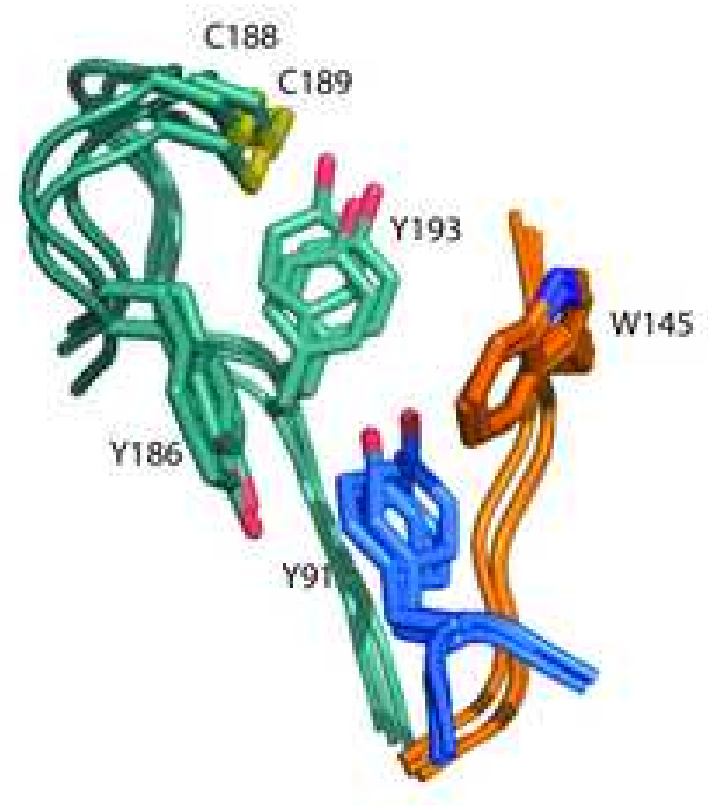

(b)

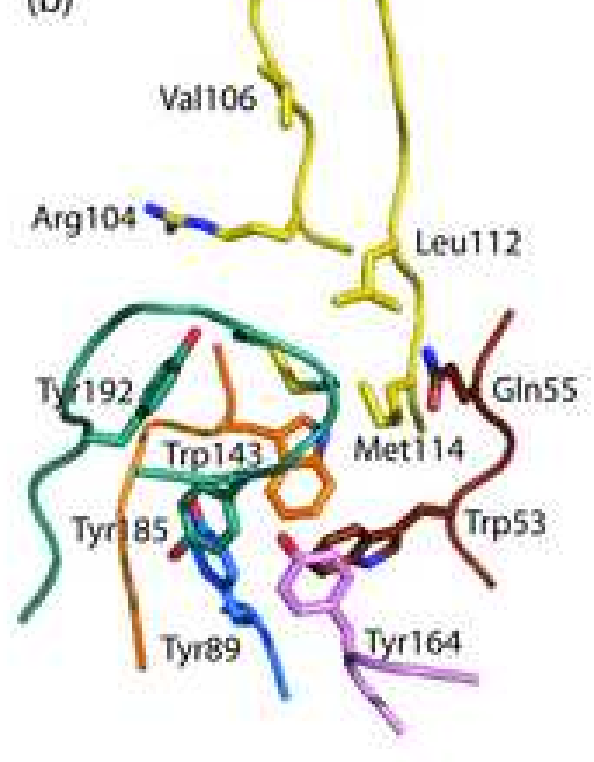

(d)

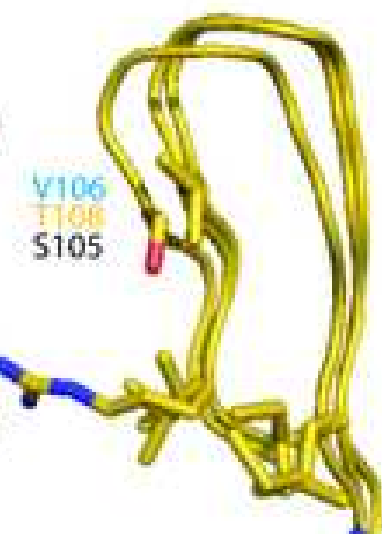

L.112

1111

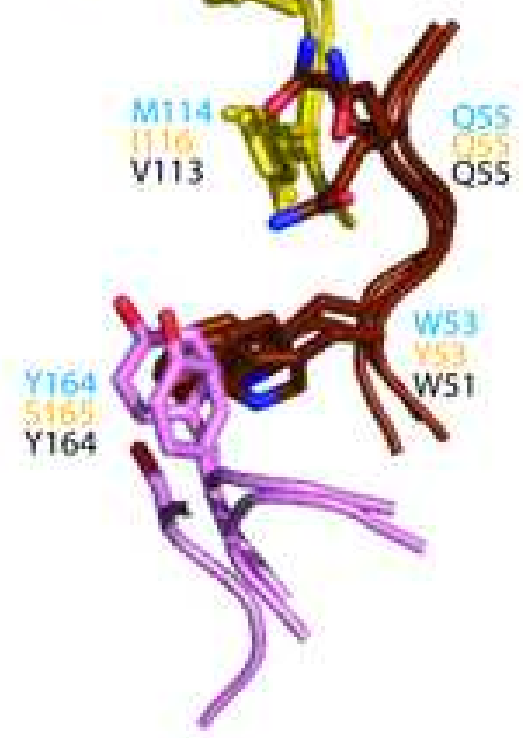

LSAChBP AcAChBE BtAChBP 


\section{Figure3}
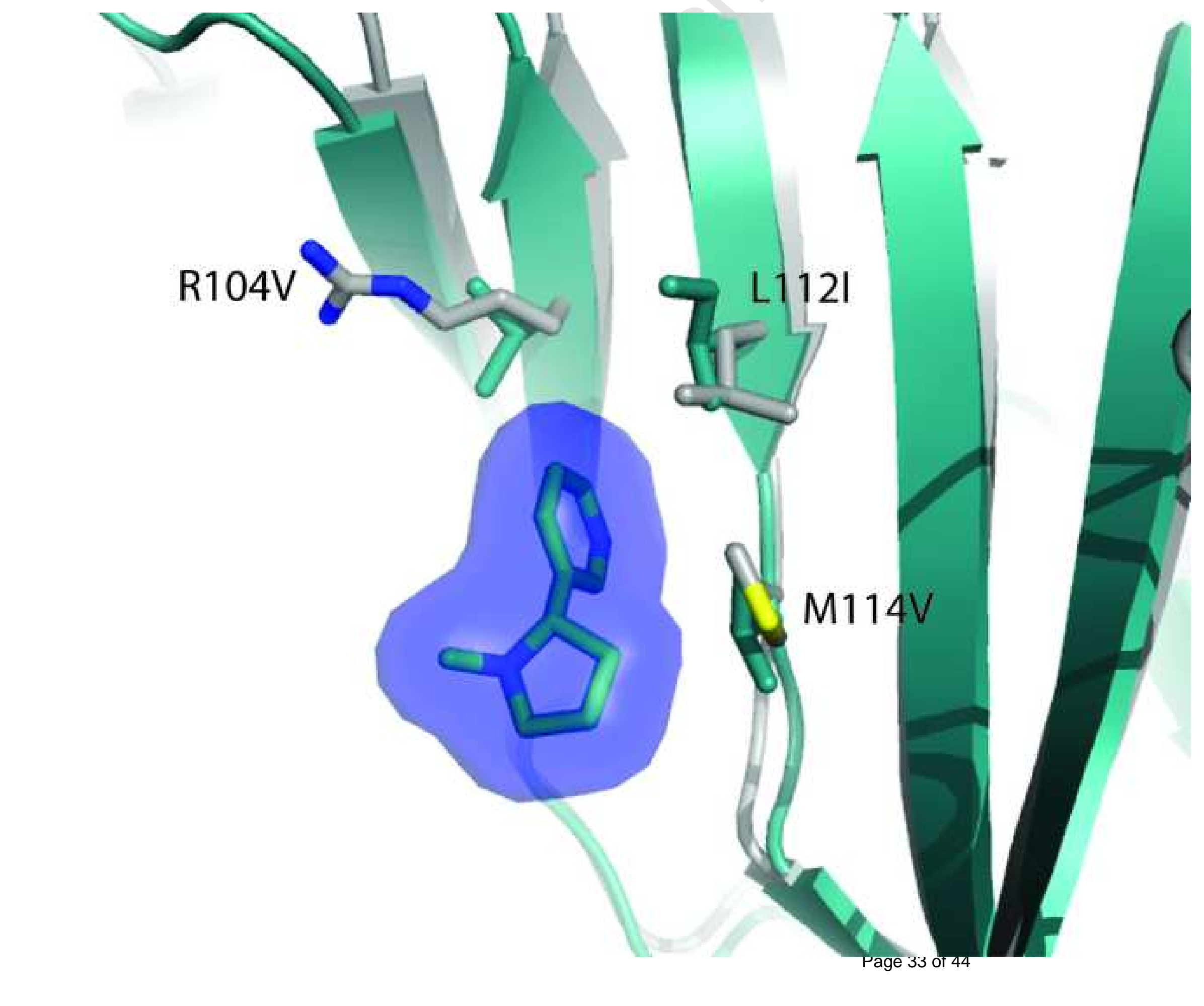
(a)
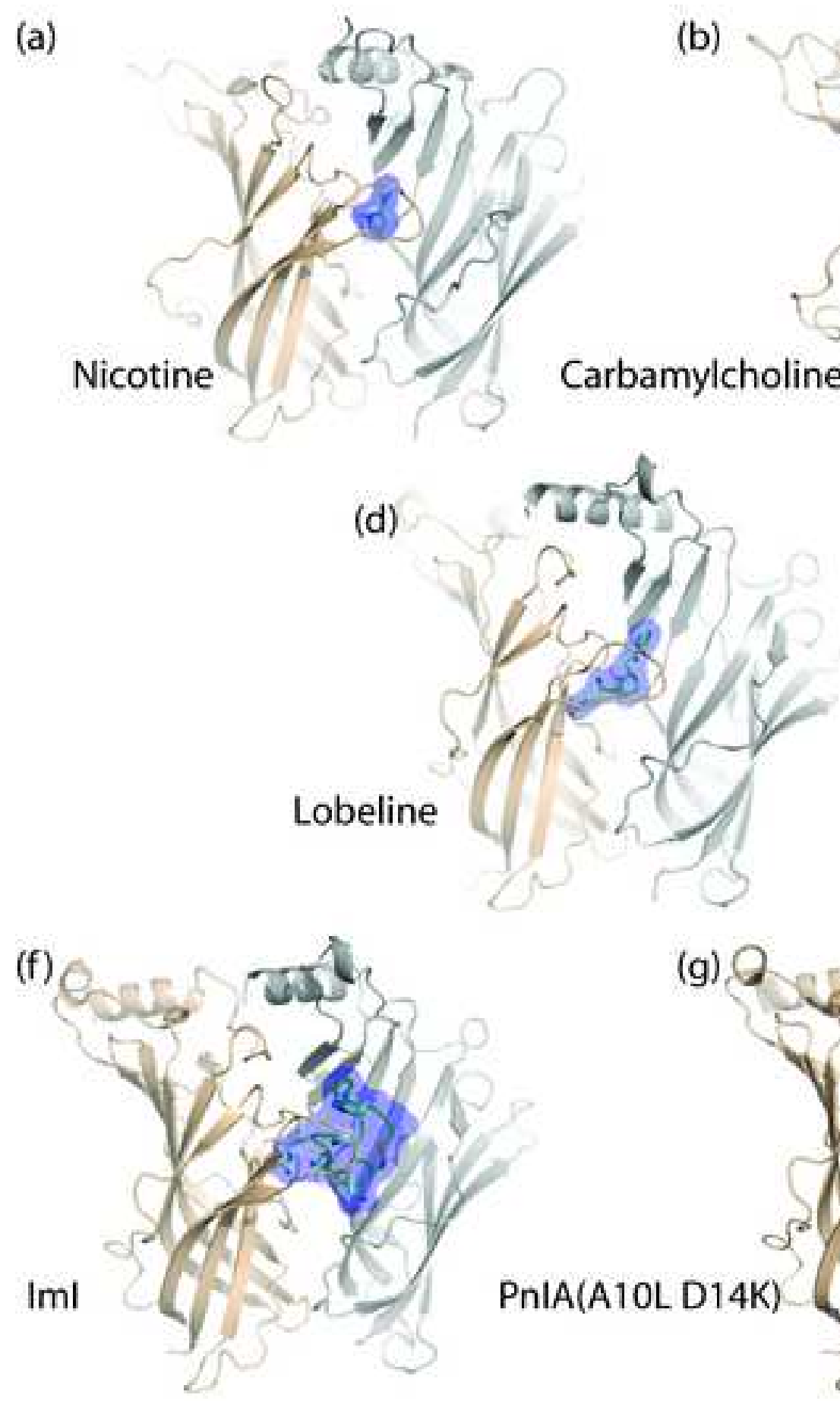

(b)
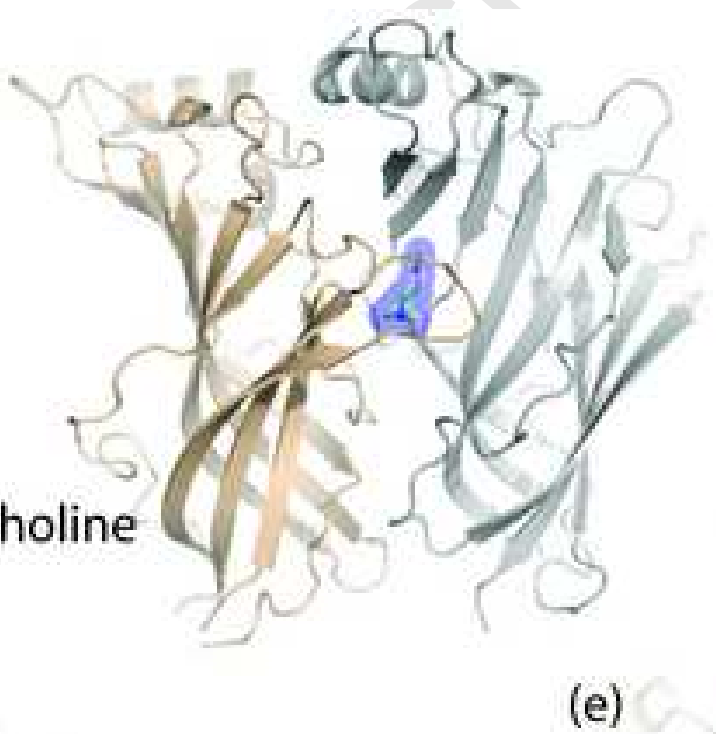

(c)

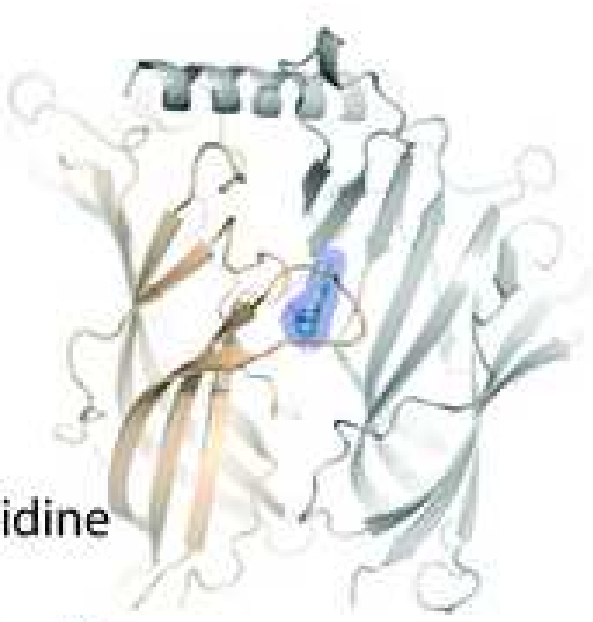

Epibatidine

Methyllycaconitine
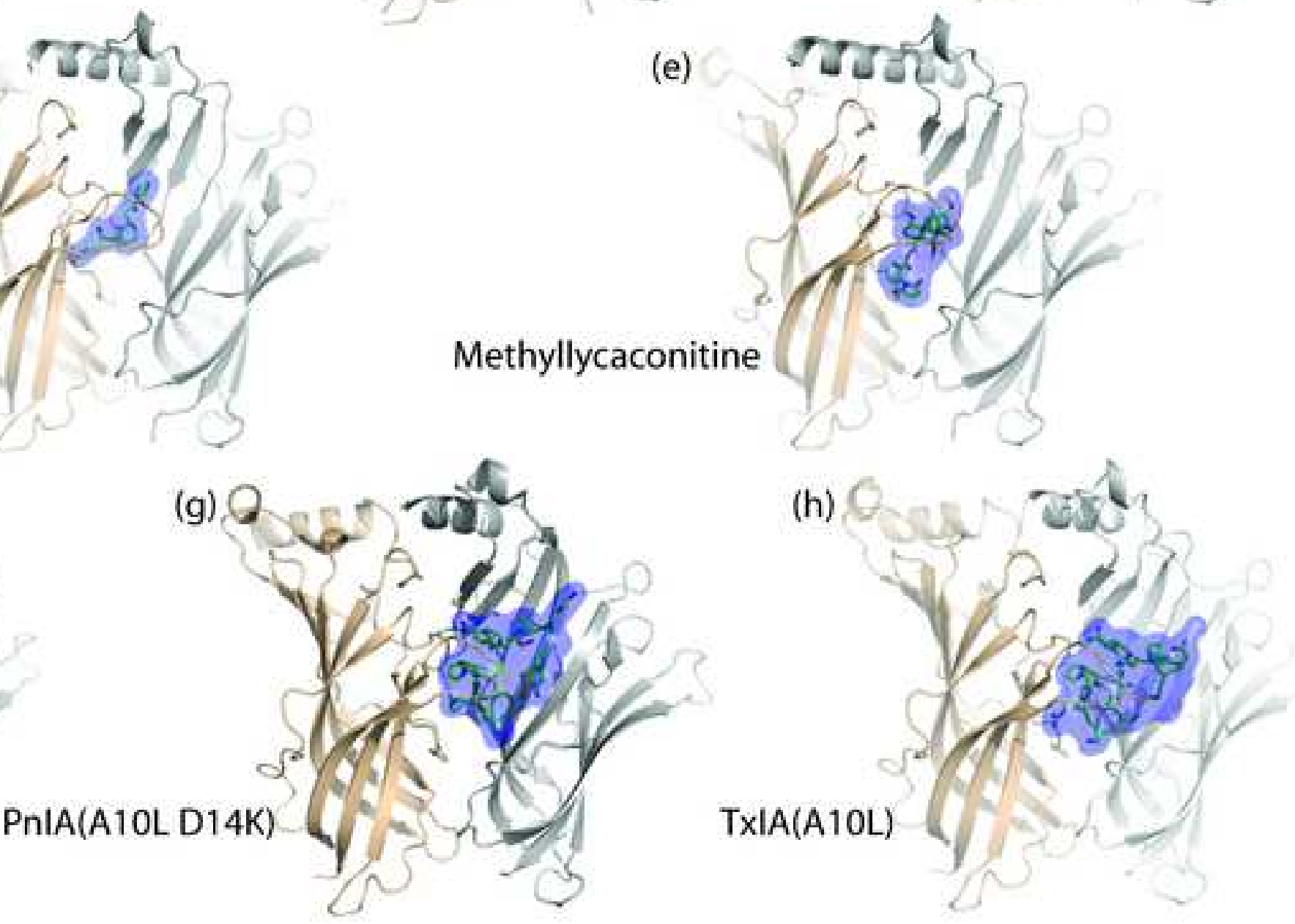

rage 34 or 44 
(a)

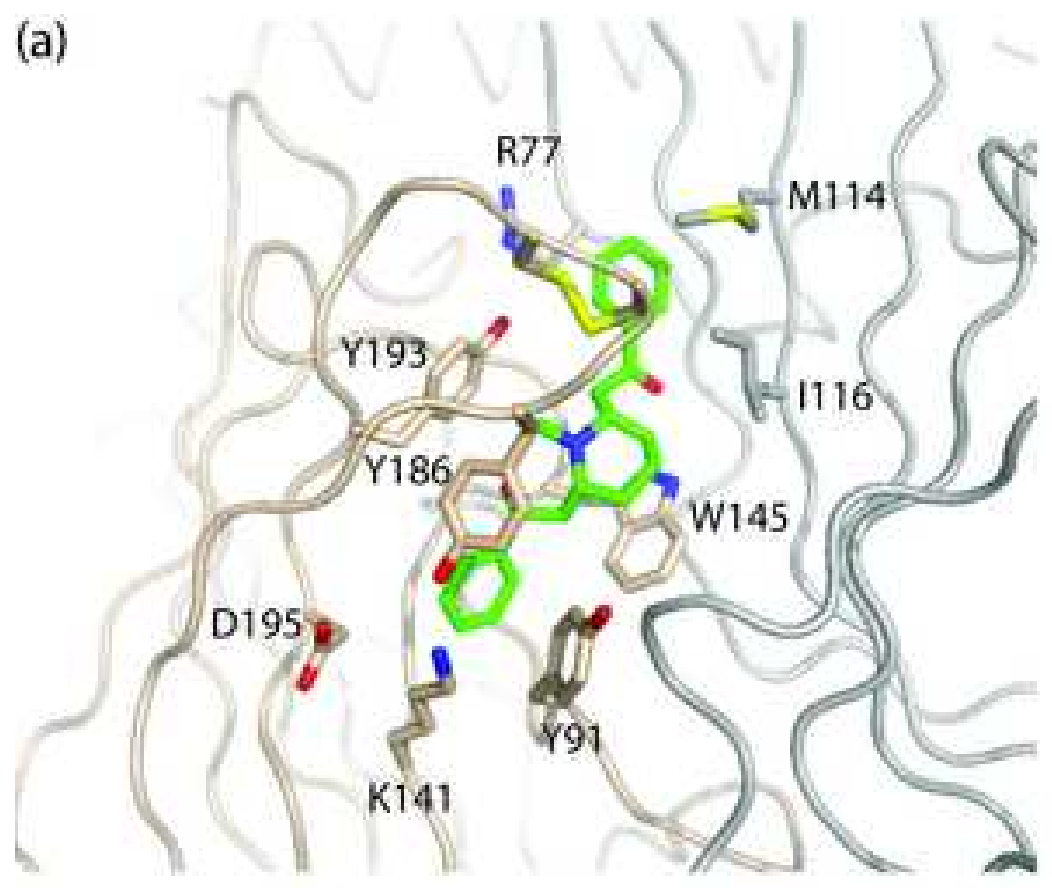

(b)
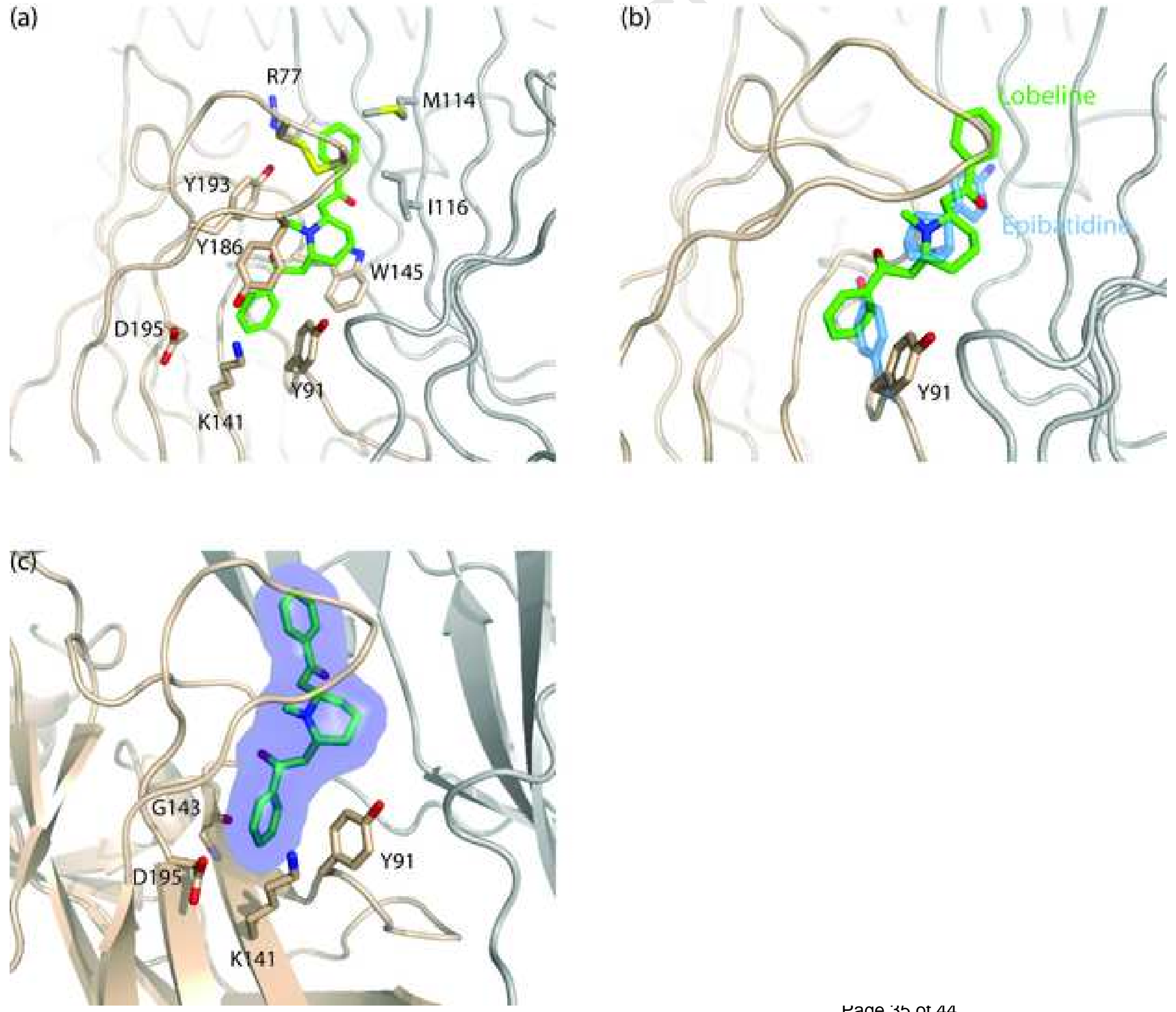


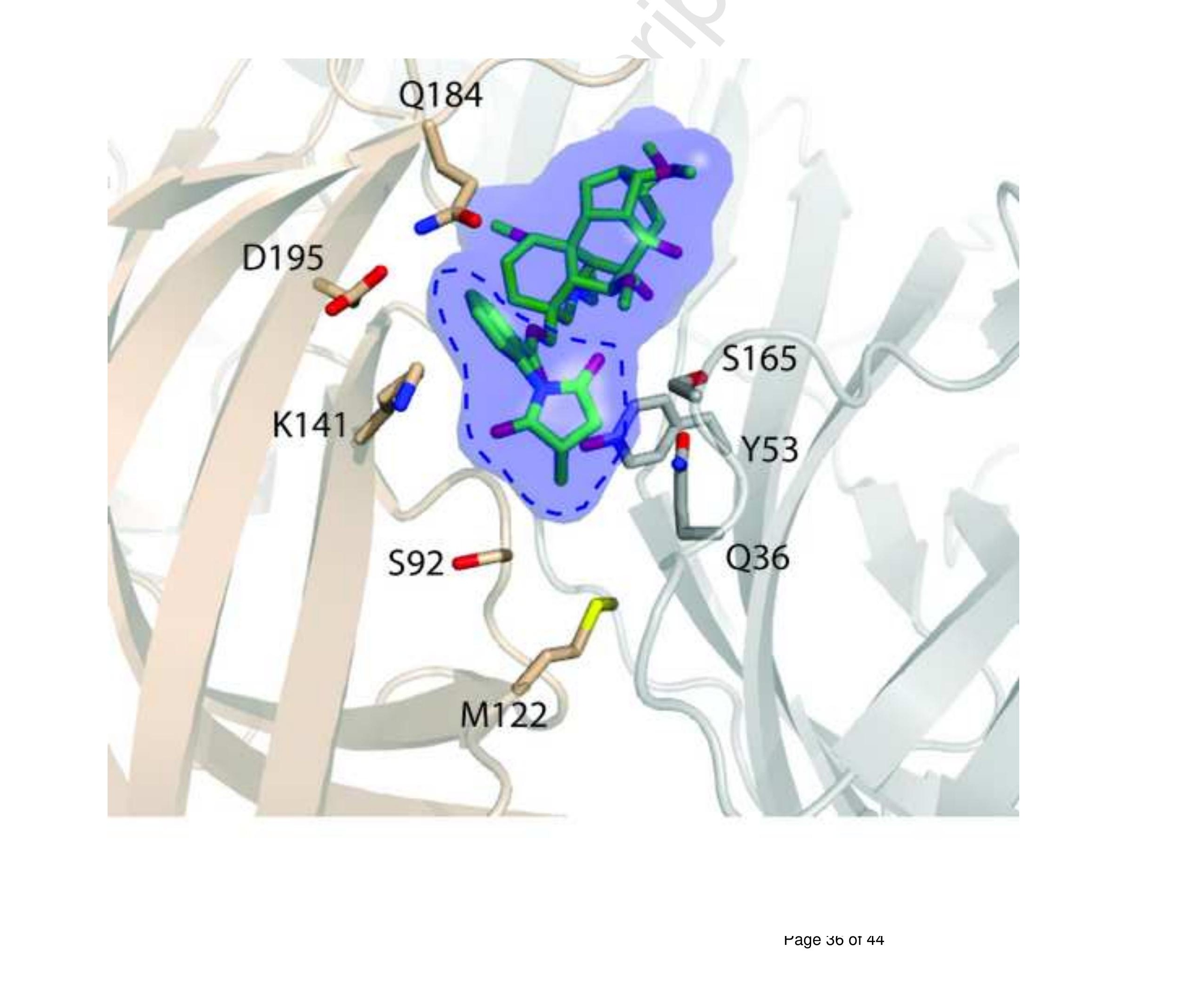

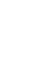

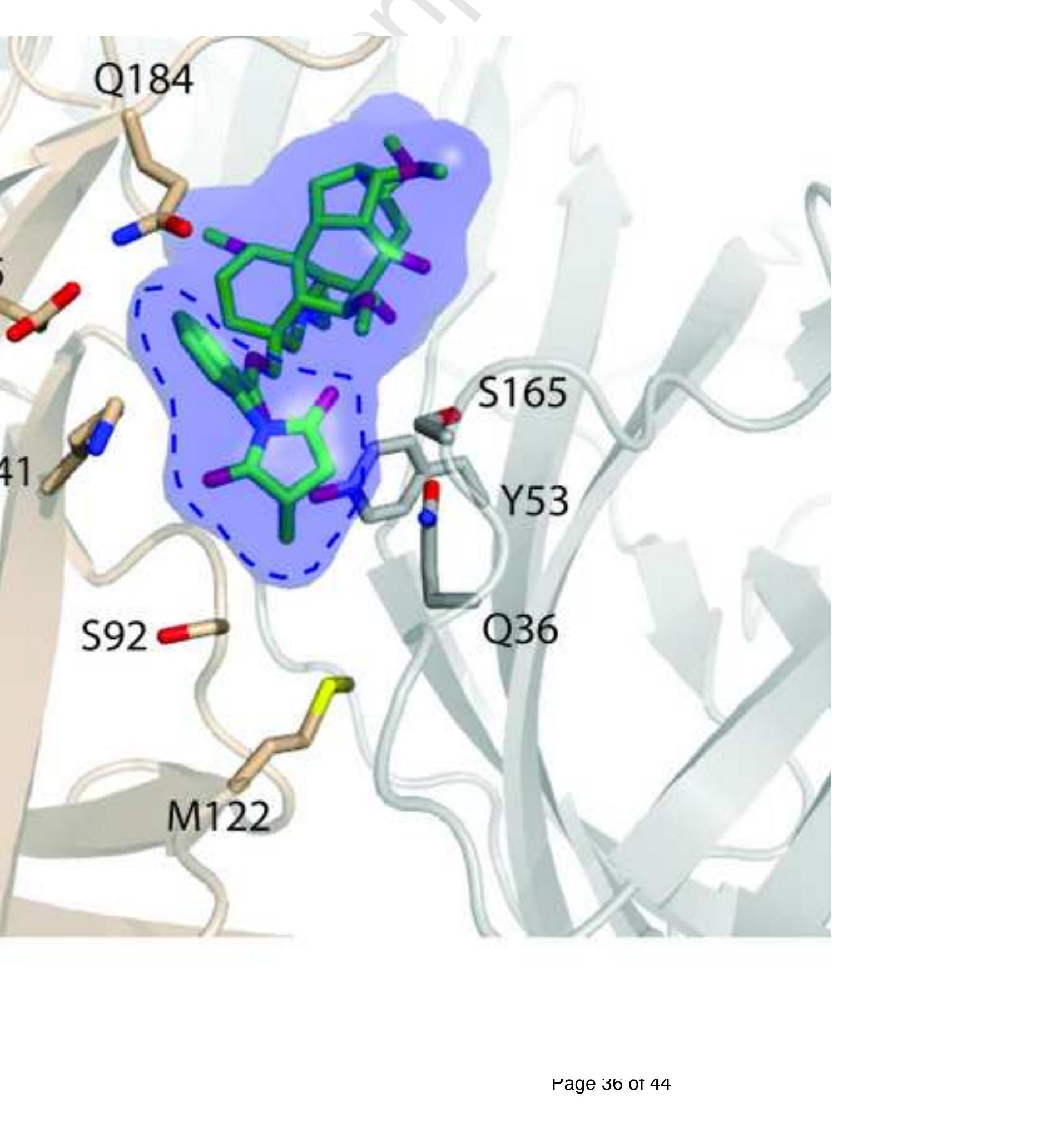

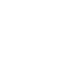
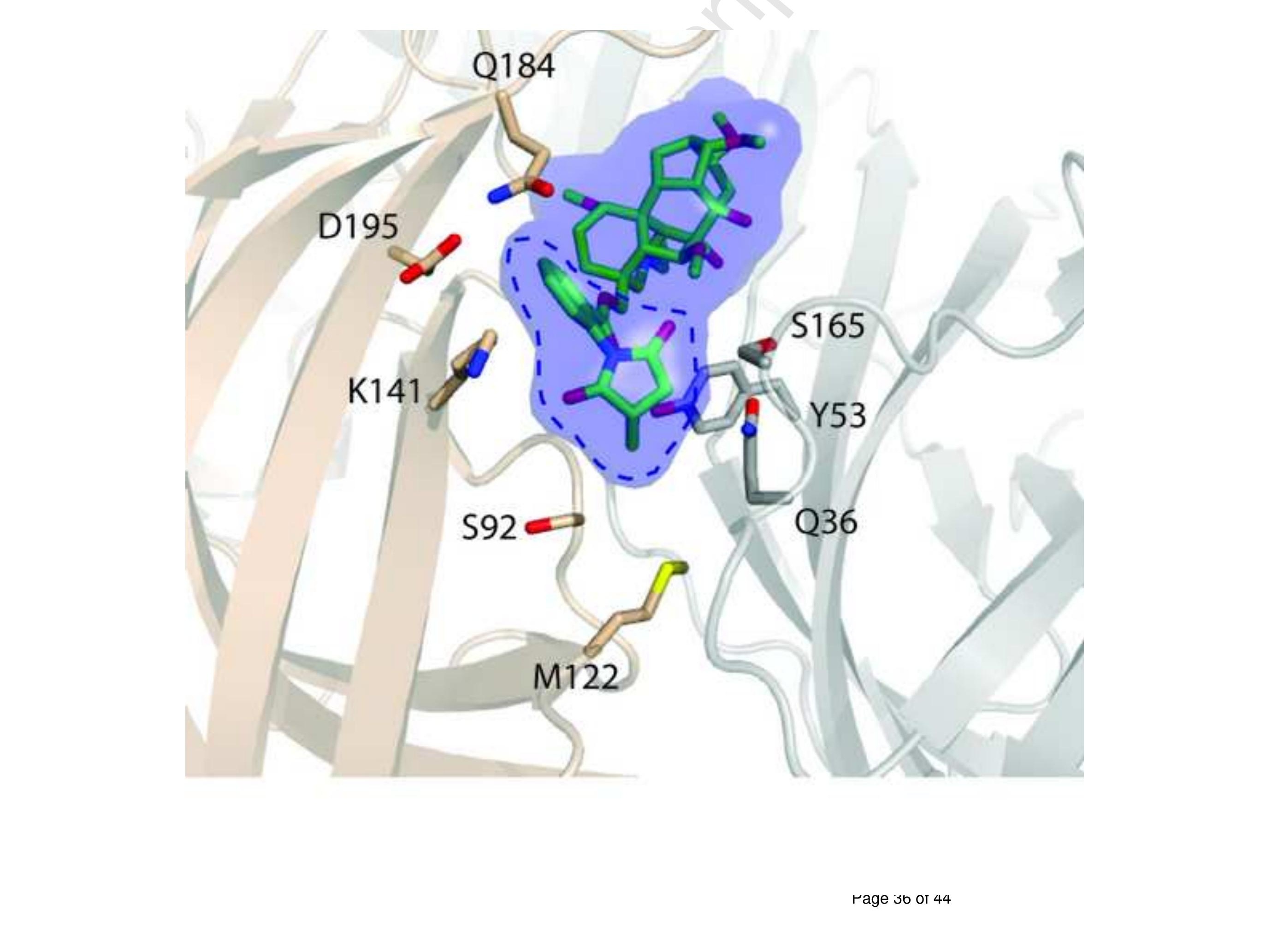

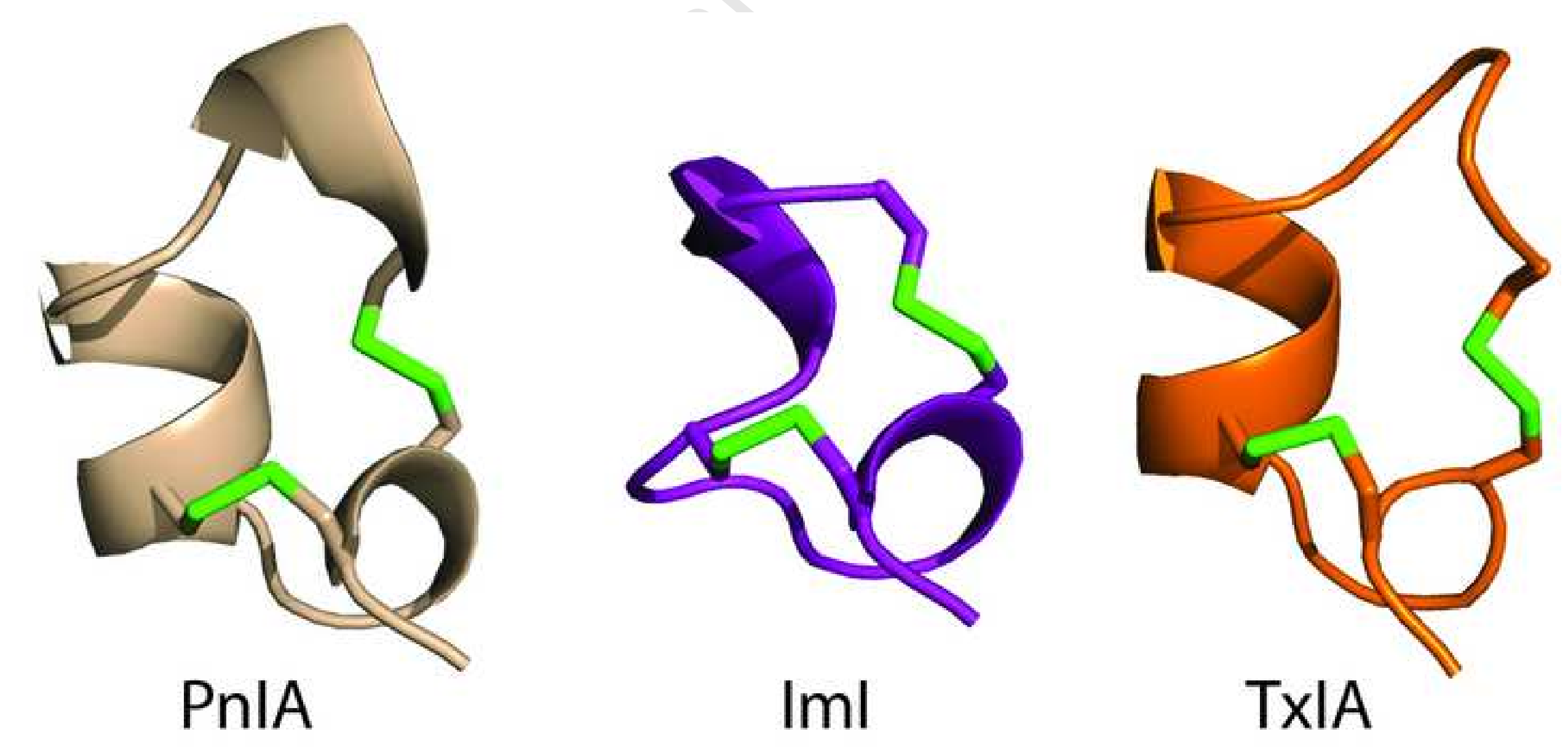

Page 37 of 44 


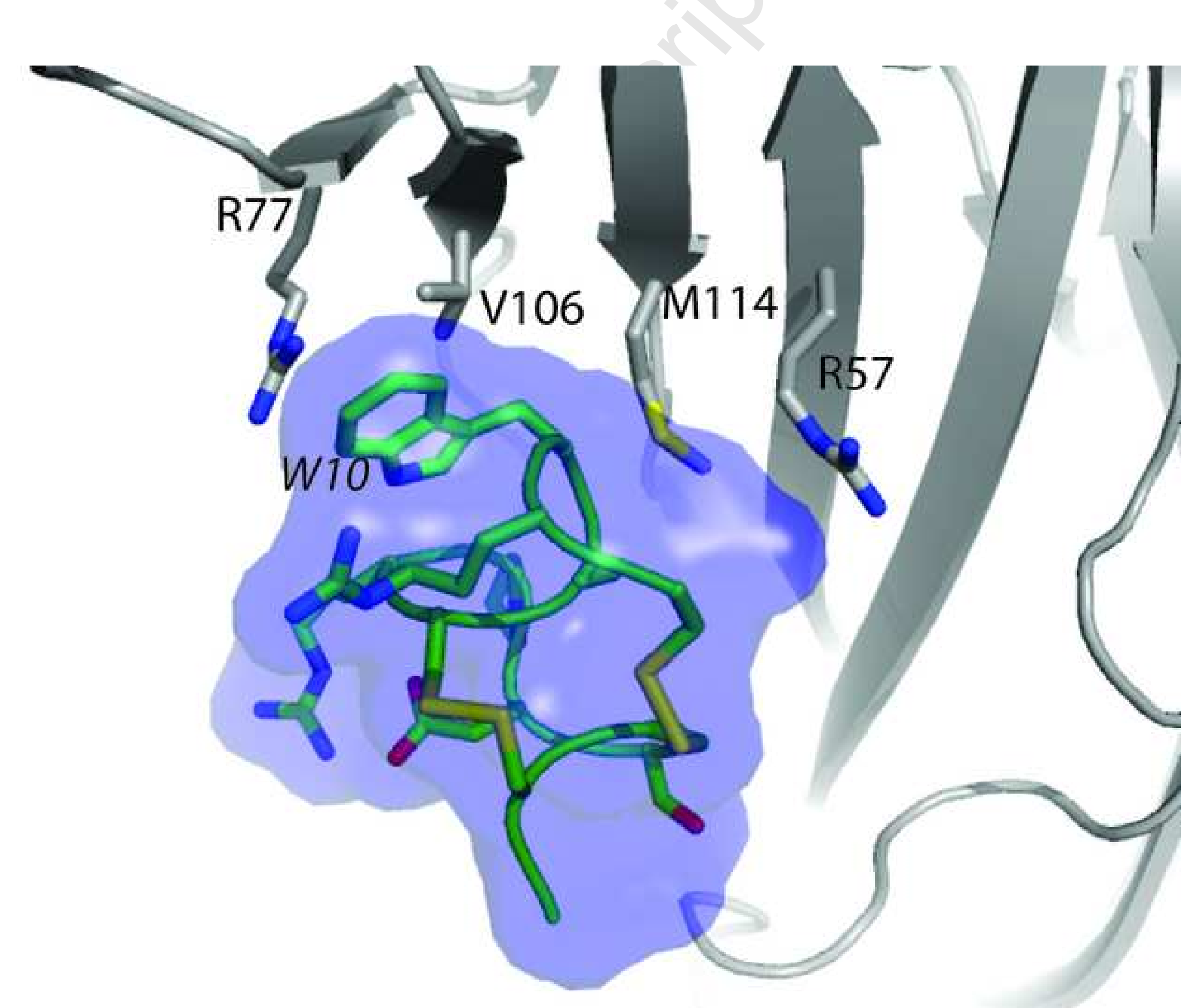

rage 3y or 44 


\section{Figure10}

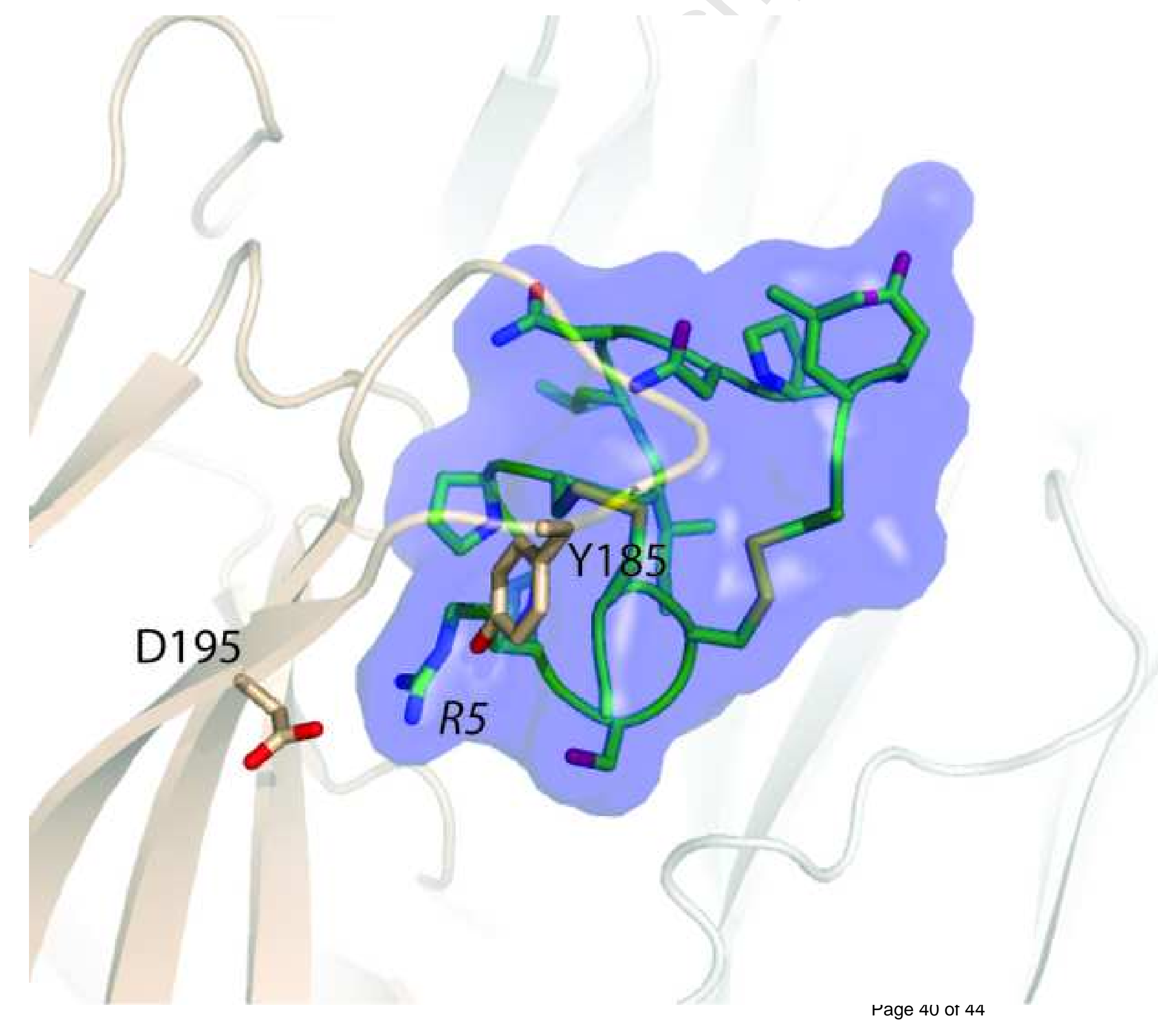

D195

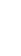

rage 40 or 44 

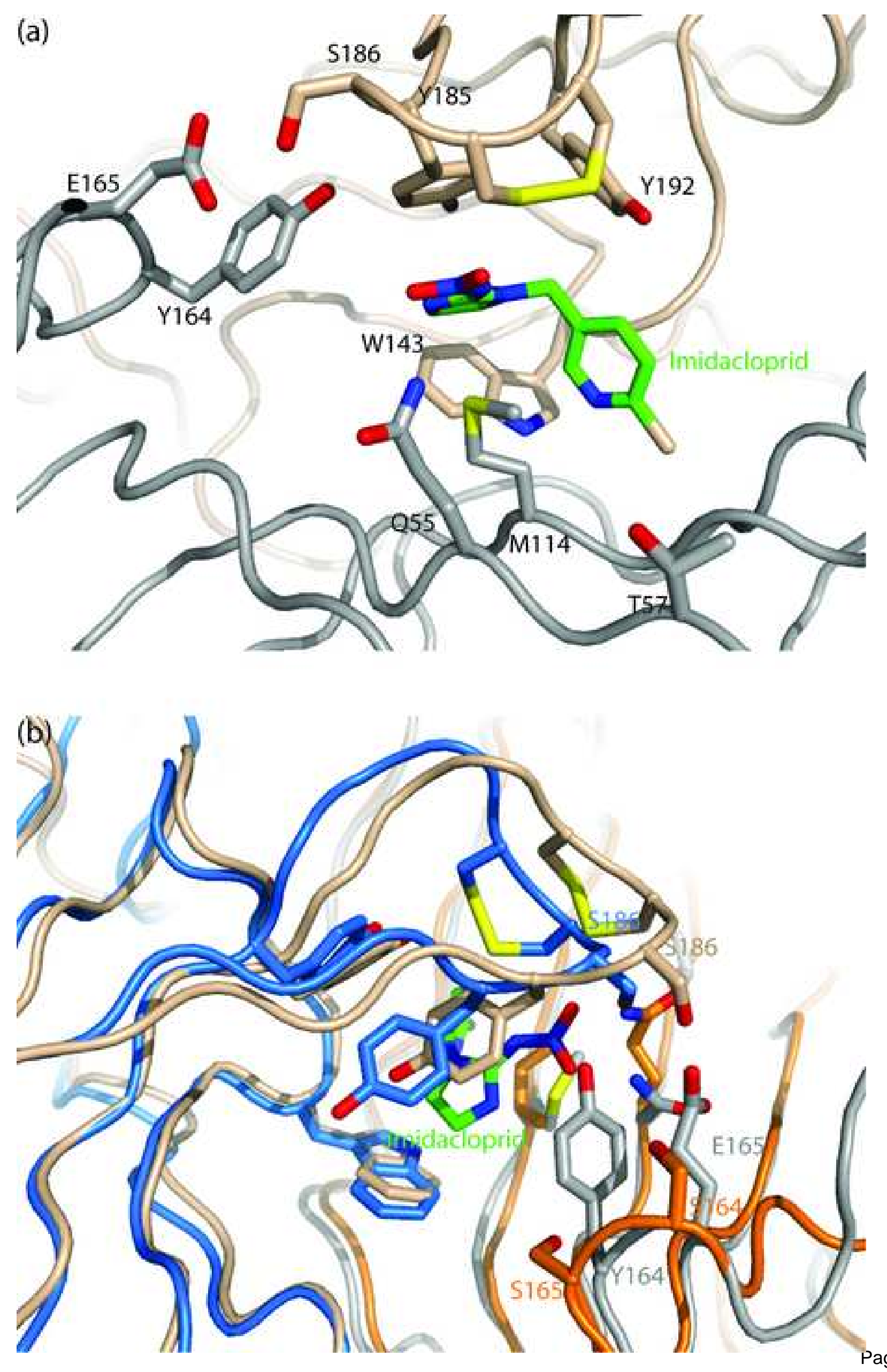


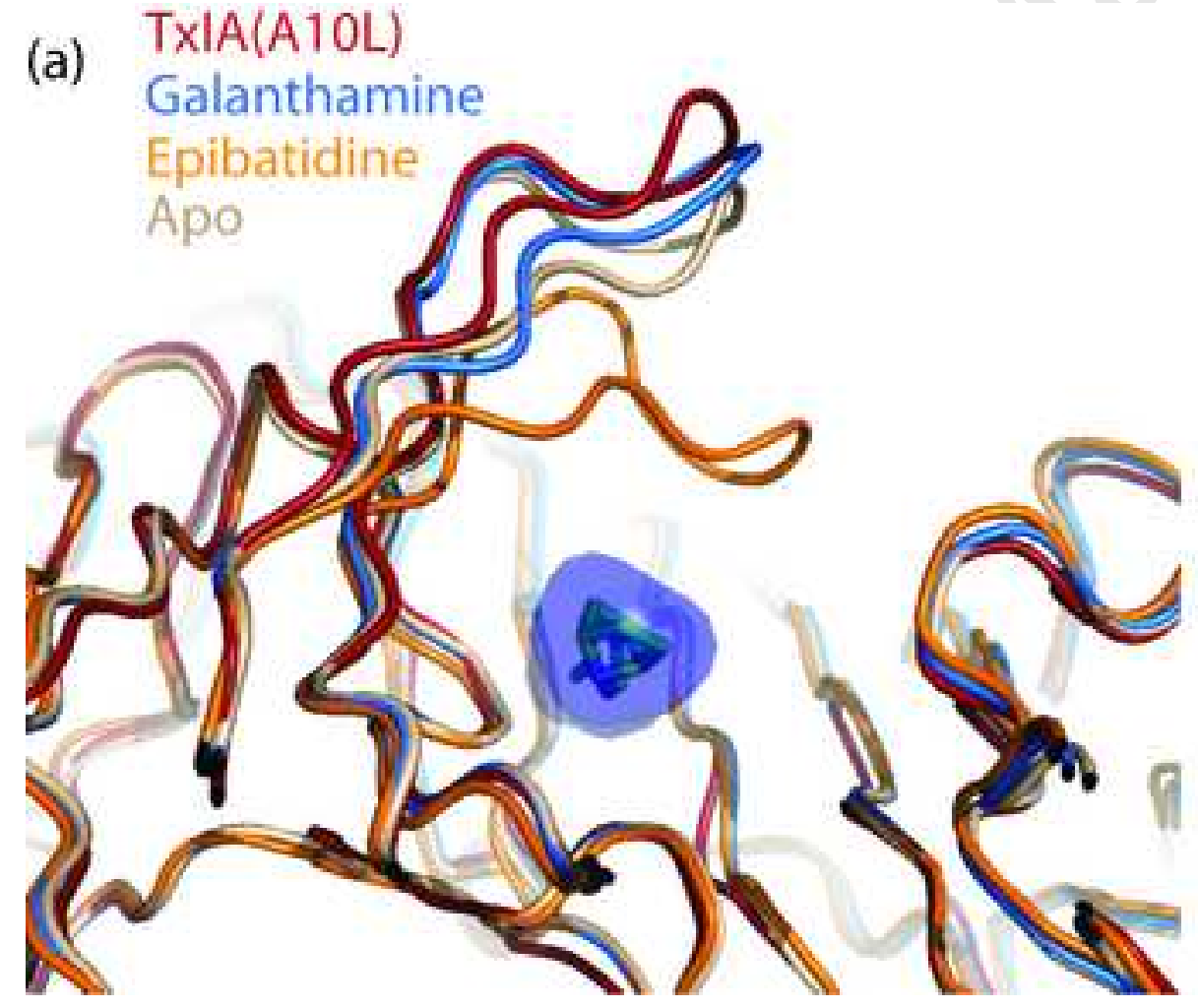

(b)

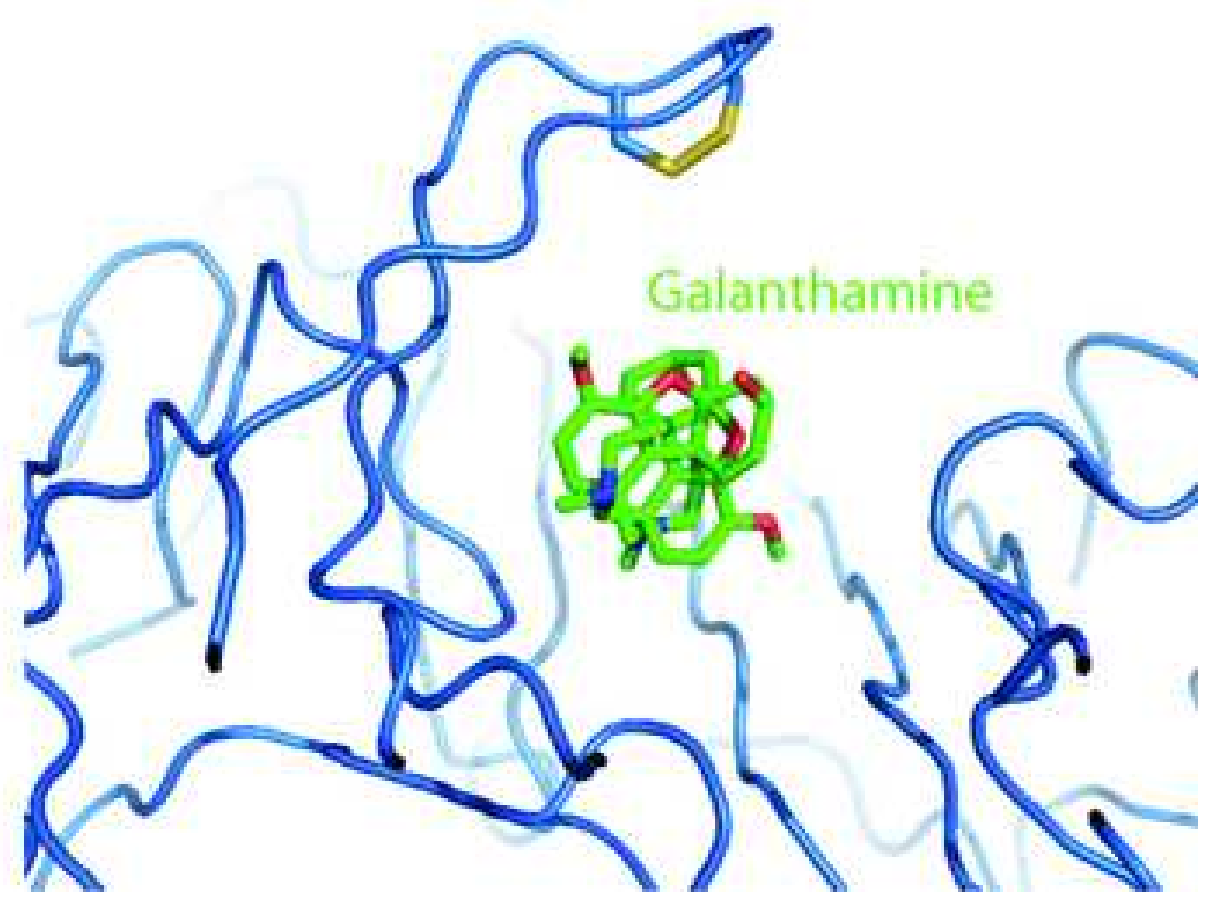


(a)

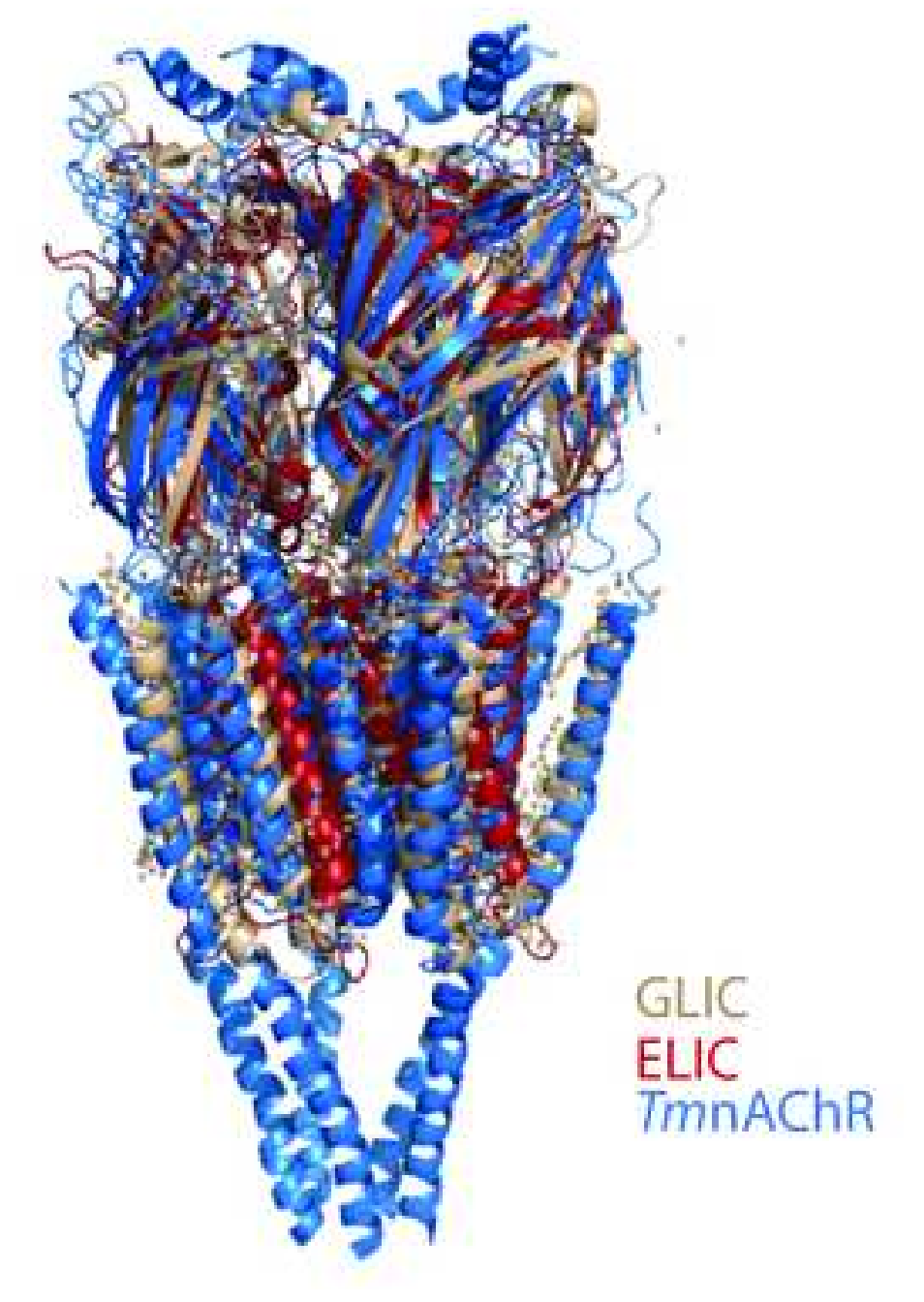

(b)

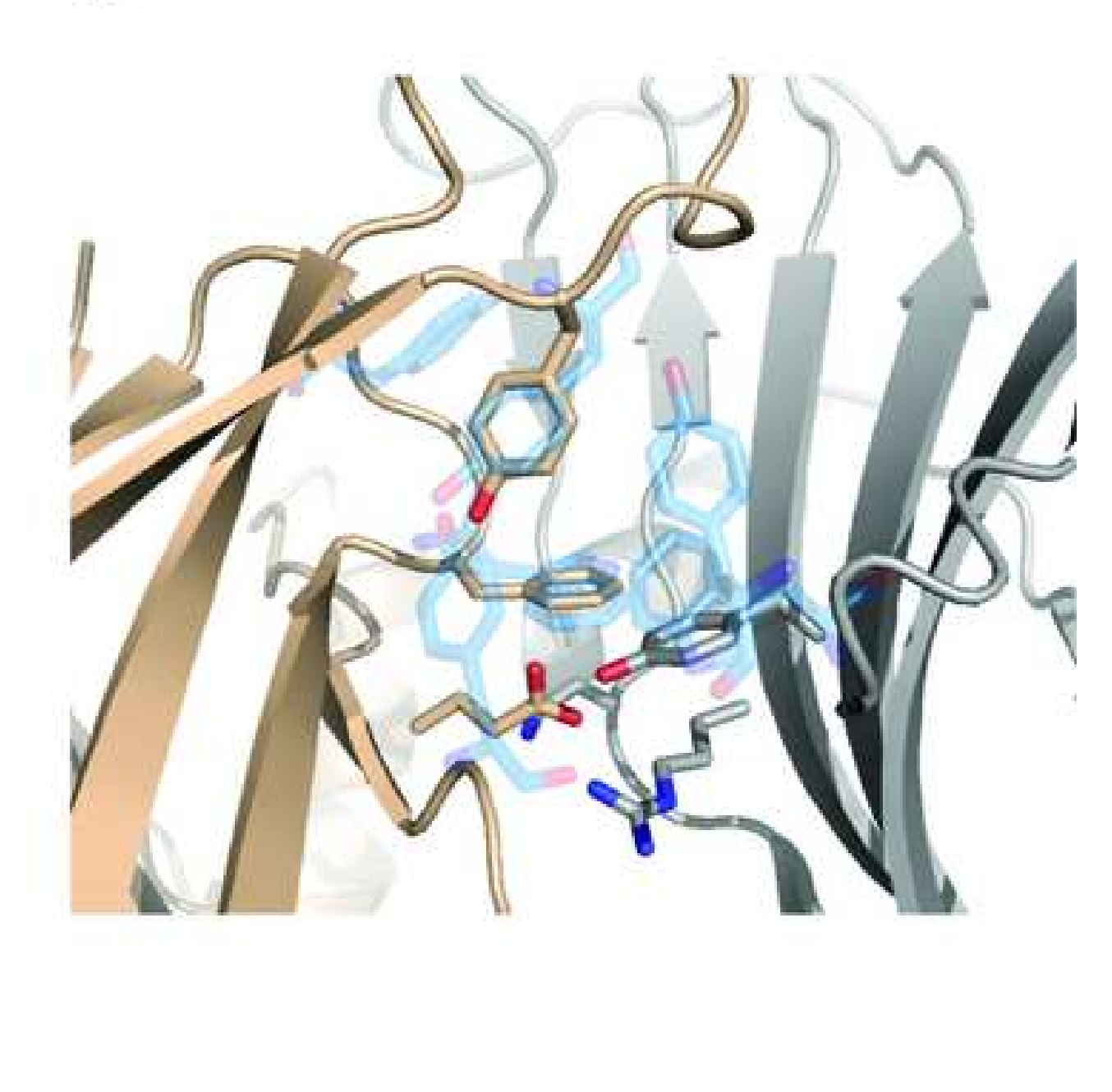

(b)

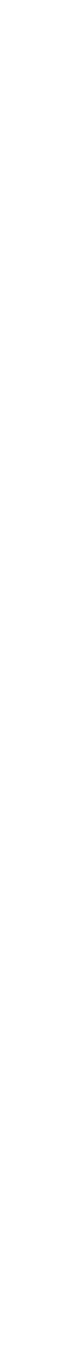


